\title{
Interferometric Synthetic Aperture Radar (SAR) Missions Employing Formation Flying
}

\author{
A German Earth satellite system is designed to produce data on forest structure, \\ biomass, tectonic shifts and glacier movements, and to advance understanding \\ of Earth dynamics.
}

\author{
By Gerhard Krieger, Senior Member IEeE, Irena Hajnsex, Senior Member IEeE, \\ Konstantinos Panagiotis Papathanassiou, Senior Member IEEE, \\ Marwan Younis, Senior Member IEEE, and Alberto Moreira, Fellow IEEE
}

ABSTRACT | This paper presents an overview of single-pass interferometric Synthetic Aperture Radar (SAR) missions employing two or more satellites flying in a close formation. The simultaneous reception of the scattered radar echoes from different viewing directions by multiple spatially distributed antennas enables the acquisition of unique Earth observation products for environmental and climate monitoring. After a short introduction to the basic principles and applications of SAR interferometry, designs for the twin satellite missions TanDEM- $X$ and Tandem- $L$ are presented. The primary objective of TanDEM-X (TerraSAR-X add-on for Digital Elevation Measurement) is the generation of a global Digital Elevation Model (DEM) with unprecedented accuracy as the basis for a wide range of scientific research as well as for commercial DEM production. This goal is achieved by enhancing the TerraSAR-X mission with a second TerraSAR-X like satellite that will be launched in spring 2010. Both satellites act then as a large single-pass SAR interferometer with the opportunity for flexible baseline selection. Building upon the experience gathered with the TanDEM-X mission design, the fully polarimetric L-band twin satellite formation Tandem-L is proposed.

Manuscript received June 5, 2009; revised September 14, 2009 and November 27, 2009. First published March 15, 2010; current version published May 5, 2010

G. Krieger, K. P. Papathanassiou, M. Younis, and A. Moreira are with the German Aerospace Center, Microwaves and Radar Institute, 82234 Wessling, Germany (e-mail: gerhard.krieger@dlr.de; kostas.papathanassiou@dlr.de;

marwan.younis@dlr.de; alberto.moreira@dlr.de).

I. Hajnsek is with the German Aerospace Center, Microwaves and Radar Institute, 82234 Wessling, Germany, and with the Institute of Environmental Engineering, ETH Zürich, 8093 Zürich, Switzerland (e-mail: irena.hajnsek@dlr.de; ihajnsek@ethz.ch).

Digital Object Identifier: 10.1109/JPROC.2009.2038948
Important objectives of this highly capable interferometric SAR mission are the global acquisition of three-dimensional forest structure and biomass inventories, large-scale measurements of millimetric displacements due to tectonic shifts, and systematic observations of glacier movements. The sophisticated mission concept and the high data-acquisition capacity of Tandem-L will moreover provide a unique data source to systematically observe, analyze, and quantify the dynamics of a wide range of additional processes in the bio-, litho-, hydro-, and cryosphere. By this, Tandem- $L$ will be an essential step to advance our understanding of the Earth system and its intricate dynamics. Enabling technologies and techniques are described in detail. An outlook on future interferometric and tomographic concepts and developments, including multistatic SAR systems with multiple receivers, is provided.

KEYWORDS | Bistatic; digital beamforming; Digital Elevation Model (DEM); earth observation; interferometry; multistatic; polarimetry; remote sensing; Synthetic Aperture Radar (SAR); Tandem-L; TanDEM-X; TerraSAR-X; tomography

\section{INTRODUCTION}

For more than 30 years, spaceborne Synthetic Aperture Radar (SAR) systems have demonstrated their outstanding capabilities for numerous Earth observation applications that greatly benefit from the ability to acquire highresolution radar images independent of sunlight illumination and weather conditions [1]-[3]. The range of applications further expanded with the introduction of interferometric techniques in the early 1990s (see [4]-[9] for excellent reviews on SAR interferometry). Radar 
interferometry is based on the coherent combination of two or more complex SAR images and has matured to a well-established remote sensing technique over the last 15 years. Recent progress includes the development of advanced multichannel SAR techniques like polarimetric interferometry and tomography that both provide unique opportunities for environmental and climate monitoring. So far, most interferometric applications have been based on a repeat-pass orbit scenario, allowing, for example, the measurement of large-scale surface deformations with an accuracy of a few millimeters over timescales ranging from weeks up to decades. Another opportunity is the generation of digital elevation models (DEMs), but the accuracy of repeat-pass interferometry is limited by slight scene and atmosphere changes between the individual acquisitions, causing a so-called temporal decorrelation and large-scale phase errors.

This severe limitation can be overcome by spaceborne single-pass SAR interferometry, which enables the costefficient generation of worldwide consistent, highly accurate, and up-to-date DEMs in short time intervals. The implementation of single-pass interferometric systems in space opens furthermore the door to a new set of unique applications. One example is the measurement of the three-dimensional (3-D) structure of natural volume scatterers by polarimetric SAR interferometry (Pol-InSAR). This powerful radar remote sensing technique allows for the reliable retrieval of important bio- and geophysical parameters like above-ground forest biomass, which represents an essential climate variable as identified by the Intergovernmental Panel on Climate Change (IPCC). The paper focuses on the design of two innovative single-pass interferometric SAR missions.

- TanDEM-X (TerraSAR-X add-on for Digital Elevation Measurement) is the first single-pass radar interferometer in space that employs two SAR satellites flying in a closely controlled formation (see Fig. 1). The opportunity to precisely adjust the cross-track baselines between a few hundred meters and several kilometers enables the acquisi-

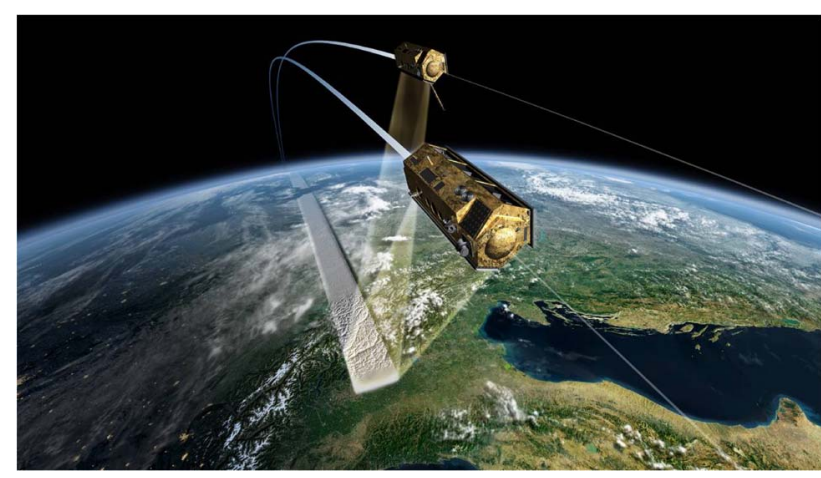

Fig. 1. Artist's view of the TanDEM-X satellite formation. tion of a global DEM of unprecedented accuracy as well as the demonstration of new bistatic and multistatic SAR techniques and applications. The launch of TanDEM-X is planned for spring 2010, and the global DEM should be available after 3-4 years.

- Tandem- $L$ is a proposal for a next-generation single-pass interferometric and fully polarimetric L-band radar mission that systematically monitors dynamic processes in the Earth environmental system using advanced SAR techniques and technologies. A primary goal of Tandem- $\mathrm{L}$ is the estimation of above-ground forest biomass with an accuracy of $20 \%$ on a global scale. Annual biomass changes will be measured throughout the mission lifetime of 5-7 years as well. In addition, singlepass polarimetric SAR interferometry enables also the measurement of bare soil topography as complementary information to the surface DEM that will be provided by the TanDEM-X mission.

This paper is organized as follows. Section II provides an introduction to the basic principles and applications of SAR interferometry. Sections III and IV form the core of the paper and provide an overview of the TanDEM-X and Tandem-L mission designs, respectively. Enabling technologies and techniques are described in detail for both missions. Section V gives an outlook on future interferometric and tomographic mission concepts and developments, including multistatic SAR systems. The paper concludes with a short summary in Section VI.

\section{SPACEBORNE SAR INTERFEROMETRY}

SAR interferometry is a powerful and well-established remote sensing technique for the quantitative measurement of important bio- and geophysical parameters of the Earth's surface. By exploiting the phase difference between pairs of coherent radar signals, SAR interferometry enables relative range measurements with subwavelength accuracy. Numerous terrestrial applications have been demonstrated with airborne experiments [10]-[16] and during spaceborne SAR missions [17]-[35].

\section{A. Application Examples}

A prominent application of SAR interferometry is topographic mapping, which allows for the operational generation of large-scale DEMs with high accuracy [10], [11], [17], [20]. Fig. 2 shows an example of a glacier DEM derived from cross-track interferometry. The interferometric data were acquired by an airborne SAR system, which employs two vertically displaced antennas to obtain a pair of coherent SAR images from slightly different view angles in a single pass. Accurate DEMs are of fundamental importance for a wide range of scientific and commercial applications ranging from mere cartographic mapping to sophisticated ecological studies [36], [37]. Precise knowledge about topography is furthermore required for 


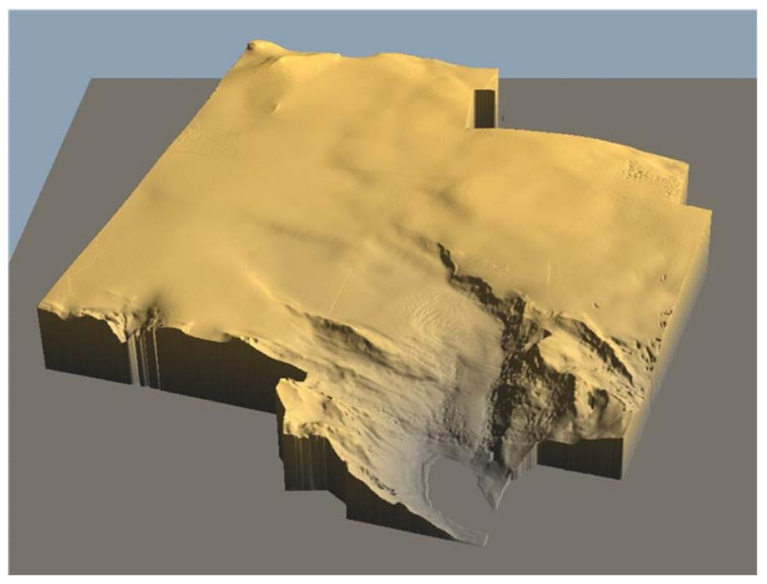

Fig. 2. DEM of the Svartisen glacier, Norway, derived from X-band single-pass cross-track interferometry ( $X$-band dual antenna data acquired by DLR's airborne E-SAR system).

orthorectification of optical images or during radiometric calibration and geocoding of conventional SAR images.

The capability of radar interferometers can be enhanced with additional radar observables. An example is Pol-InSAR, which combines the capabilities of radar polarimetry to separate different scattering mechanisms with the vertical resolution capabilities of cross-track interferometry [32], [39]. This combination enables the estimation of the vertical reflectivity function of semitransparent volume scatterers, including accurate measurements of vegetation height and its underlying topography. By this, it has great potential to provide global biomass estimates as required for a better understanding of the global carbon cycle. Fig. 3 shows an example of forest

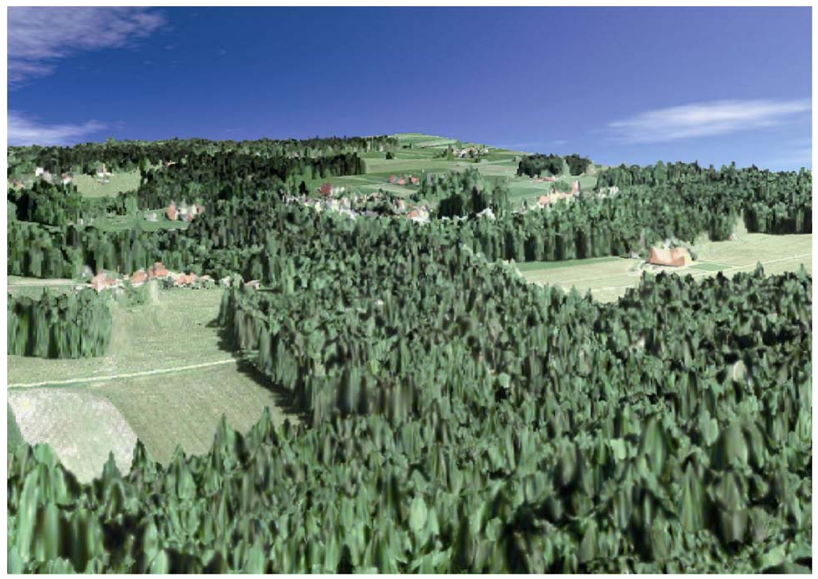

Fig. 3. Forest heights derived from the Pol-InSAR technique overlaid on a Google map from Traunstein, Germany (forest height retrieval based on two fully-polarimetric $L$-band data sets acquired by DLR's airborne E-SAR system).

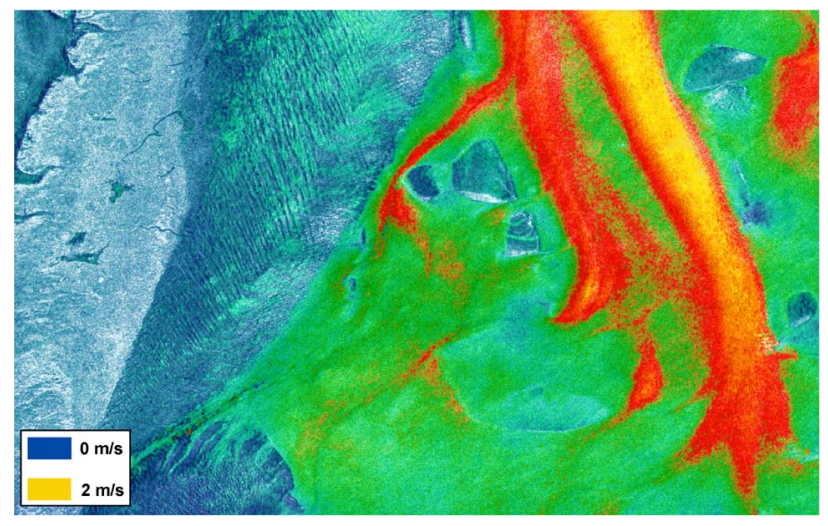

Fig. 4. Measurement of water current velocities in the Wadden Sea, Ameland, The Netherlands, by along-track interferometry (X-band data acquired in ping-pong mode by DLR's airborne E-SAR system).

heights that have been derived by employing the Pol-InSAR technique to a pair of fully polarimetric airborne SAR images acquired in L-band. For visualization, the measured forest heights are overlaid on a Google map of Traunstein. The height estimation with Pol-InSAR has been successfully demonstrated on various forest types, ranging from boreal to tropical forests, and achieves typical accuracies on the order of $10 \%$ [16], [40], [41], [43], [44]. The threedimensional information layer derived with the Pol-InSAR technique is a good example of how future satellite systems can increase our understanding of the environment and its changes.

Other outstanding applications emerge from alongtrack interferometry, which evaluates the phase difference of two radar images acquired at different times [12]. This phase comparison enables a precise estimation of radial displacements with millimetric accuracy. By varying the temporal baseline between the interferometric acquisitions, velocities ranging from several meters per second down to a few millimeters per year can accurately be measured [13], [19]. Fig. 4 shows as an example the water current velocities in a tideland region derived from the coherent combination of two SAR images acquired by an aircraft with two radar antennas that have been displaced in the along-track direction. Important applications covering the whole range of potential time scales are the detection of moving objects like cars or ships [45], [46], the observation of ocean surface currents [12], [13], the measurement of sea ice drift and glacier flow [23], [31], the study of seismic deformations and volcanic activities [21], [30], and the monitoring of land subsidence [33], [34]. Further potential arises from a comparison of the coherence between several data acquisitions, which can be used for land classification and change detection [25]-[29].

Many of these interferometric applications have successfully been demonstrated in a single-pass configuration on airborne platforms or by evaluating the radar data from 
Table 1 Comparison of the Digital Terrain Elevation Data (DTED) and High-Resolution Terrain Information (HRTI) Standards for DEMs

\begin{tabular}{|c|c|c|c|c|}
\hline Requirement & Specification & DTED-2 & HRTI-3 & HRTI-4 \\
\hline $\begin{array}{c}\text { Relative Vertical } \\
\text { Accuracy }\end{array}$ & $\begin{array}{l}90 \% \text { linear point- } \\
\text { to-point error over } \\
\text { a } 1^{\circ} \text { cell }\end{array}$ & $\begin{array}{c}12 \mathrm{~m} \\
(\text { slope }<20 \%) \\
15 \mathrm{~m} \\
(\text { slope }>20 \%)\end{array}$ & $\begin{array}{c}2 \mathrm{~m} \\
(\text { slope }<20 \%) \\
4 \mathrm{~m} \\
(\text { slope }>20 \%)\end{array}$ & $\begin{array}{c}0.8 \mathrm{~m} \\
(\text { slope }<20 \%) \\
1 \mathrm{~m} \\
(\text { slope }>20 \%)\end{array}$ \\
\hline $\begin{array}{c}\text { Absolute Vertical } \\
\text { Accuracy }\end{array}$ & $90 \%$ linear error & $18 \mathrm{~m}$ & $10 \mathrm{~m}$ & $5 \mathrm{~m}$ \\
\hline $\begin{array}{c}\text { Horizontal } \\
\text { Accuracy }\end{array}$ & $90 \%$ circular error & $23 \mathrm{~m}$ & $10 \mathrm{~m}$ & $10 \mathrm{~m}$ \\
\hline Spatial Resolution & $\begin{array}{l}\text { independent } \\
\text { pixels }\end{array}$ & $30 \mathrm{~m}(1 \mathrm{arcsec})$ & $12 \mathrm{~m}(0.4 \mathrm{arc} \mathrm{sec})$ & $6 \mathrm{~m}(0.2 \operatorname{arcsec})$ \\
\hline
\end{tabular}

multiple satellite passes. However, airborne sensors have the disadvantage of limited coverage, which restricts their application to local or, in the best case, regional scale areas. On the other hand, spaceborne repeat-pass interferometry suffers from the long time lag between the individual data takes. As a result, the achievable accuracy of many interferometric applications is severely affected by temporal decorrelation resulting from relative scatterer movements and changes in their dielectric properties [24], [27]. A further error source is atmospheric disturbances like variations of the tropospheric water vapor or ionospheric propagation delays, which lead to spatially correlated phase shifts in the final interferogram [9]. Further common problems in repeat-pass interferometry arise from insufficient a posteriori baseline knowledge as well as the limited opportunities for precise a priori orbit tuning.

\section{B. Single-Pass Interferometry}

A first step to overcome the limitations from repeatpass interferometry was the Shuttle Radar Topography Mission (SRTM), which used a deployable boom to acquire interferometric data in a spaceborne single-pass configuration [8], [48]-[50]. This challenging mission was successfully flown in February 2000 and acquired a DEM of the Earth's landmass between $-56^{\circ}$ and $+60^{\circ}$ latitudes The interferometric performance was essentially determined by the fixed boom length of $60 \mathrm{~m}$, which limited the achievable DEM accuracy to the Digital Terrain Elevation Data level 2 (DTED-2) standard (see the third column in Table 1). A further opportunity arose in SRTM due to an additional along-track antenna separation of $7 \mathrm{~m}$, which resulted in an effective time lag of about $0.5 \mathrm{~ms}$ between the two image acquisitions. This temporal baseline has been used to demonstrate for the first time the feasibility of spaceborne along-track interferometry for applications like traffic monitoring [35] and the measurement of ocean currents [47]. However, the performance was again limited by the short length of the along-track baseline.

To overcome these fundamental limitations, several suggestions have been made to acquire interferometric data in a single pass by using two or more co-operating radar satellites flying in close formation [36], [51]-[53]. Such a multistatic satellite formation offers a natural way to implement single-pass SAR interferometry in space and enables a flexible imaging geometry with large and reconfigurable baselines, thereby increasing significantly the interferometric performance for applications like DEM generation or the extraction of vegetation parameters by polarimetric SAR interferometry. Further opportunities arise from a combination of multiple single-pass SAR interferograms acquired at different instances of time. Such repeated observations enable, e.g., the unambiguous measurement of small height changes, the determination of 3-D scatterer movements, or the observation of variations in dielectric constant and vertical scatterer structure, all without the limitations imposed by temporal decorrelation and atmospheric disturbance. A multistatic SAR is furthermore well suited for the implementation of alongtrack interferometry in space, which can be used for applications like ground moving target indication, the measurement of ocean currents, or the monitoring of sea ice drift.

\section{DEM Generation by Cross-Track Interferometry}

An essential prerequisite for high-precision cross-track and along-track interferometry is the provision of suitable baselines. For this, we consider the example of DEM generation by cross-track interferometry, where the range of suitable baselines is limited by several factors. The imaging geometry of a single-pass cross-track interferometer with two receivers is illustrated in Fig. 5.

It becomes apparent from Fig. 5 that for large satelliteto-scene distances $r_{0}$ and short baselines $B_{\perp}$, the measured range difference $\Delta r$ will be proportional to the height difference $\Delta h$. This proportionality can be expressed as (see, e.g., any of the reviews [4]-[9] for more rigorous derivations of the following equations)

$$
\Delta r=\frac{B_{\perp}}{r_{0} \sin \left(\theta_{i}\right)} \cdot \Delta h
$$




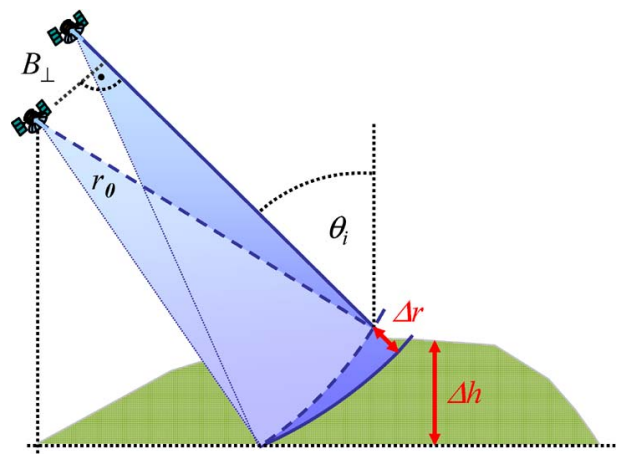

Fig. 5. Across-track SAR interferometry.

where $r_{0}$ is the slant range, $\theta_{i}$ is the local incident angle, and $B_{\perp}$ is the baseline perpendicular to the line of sight. Since the interferometric phase difference $\Delta \varphi$ is given by

$$
\Delta \varphi=\frac{2 \pi}{\lambda} \Delta r
$$

we can rewrite (1) as

$$
\frac{\Delta \varphi}{\Delta h}=k_{z}=\frac{2 \pi B_{\perp}}{\lambda r_{0} \sin \left(\theta_{i}\right)} .
$$

This equation describes the sensitivity of the radar interferometer to small height differences $\Delta h . k_{\mathrm{z}}$ is the socalled effective vertical (interferometric) wavenumber and depends only on the imaging geometry and the radar wavelength $\lambda$. It is obvious that the sensitivity can be increased by increasing the length of the perpendicular baseline $B_{\perp}$. However, the maximum useful baseline length is constrained by two factors. A first limitation is baseline decorrelation [20], [24], [54]. To understand this limitation, we imagine the recorded SAR signal as being composed of the echoes from a large number of elementary point-like scatterers. Each of these scatterers contributes to the overall radar signal with a phase shift that is proportional to its distance from the receiving antenna. If we consider now such a scatterer ensemble and vary the view angle, it becomes clear that the relative phase between the scatterers changes. This results in a fluctuation of the recorded signal, which is also known as the speckle effect. Regarding interferometry, this has the major consequence that with increasing baseline length, the phase contributions from each resolution cell become more and more different between the two SAR images. As a result, the correlation between the two complex SAR images decreases systematically with increasing baseline length until it completely vanishes. The baseline length for which the two SAR images become completely decorrelated is known as the critical baseline $B_{\perp, \text { crit }}$. For flat surfaces, this can be expressed mathematically as [20], [24], [54]

$$
B_{\perp, \text { crit }}=\frac{\lambda r_{0} \tan \left(\theta_{i}\right)}{\delta r}
$$

where $\delta r$ is the slant range resolution, which is usually approximated by $\delta r=c_{0} /\left(2 B_{r g}\right)$, with $c_{0}$ being the velocity of light and $B_{r g}$ the range or system bandwidth. The lefthand side of Fig. 6 shows the critical baselines $B_{\perp \text {,crit }}$ for Tandem-L (L-band, $85 \mathrm{MHz}$ ), Radarsat-2 (C-band, $100 \mathrm{MHz}$ ), and TerraSAR-X (X-band, $150 \mathrm{MHz}$ ) as a function of the incident angle assuming a semiactive singlepass radar interferometer with receivers at the same altitude as the transmitter. The critical baseline varies

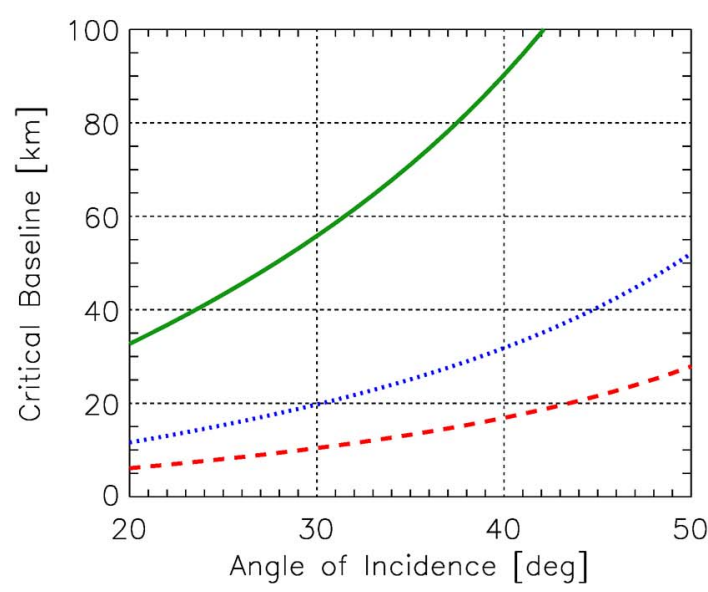

(a)

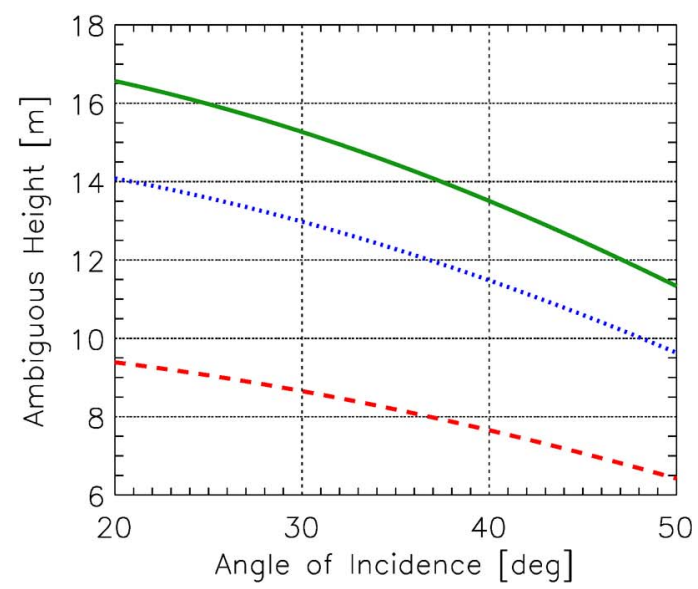

(b)

Fig. 6. (a) Critical baseline $B_{\perp, \text { crit }}$ and (b) ambiguous height for (solid) Tandem-L, (dotted) Radarsat-2, and (dashed) TerraSAR-X. 
between several kilometers for TerraSAR-X and several tens of kilometers for Tandem-L.

A second and, from a practical point of view, often more restrictive limitation for the maximum baseline length results from ambiguities in the phase-to-height conversion. For this, we consider again (3) and recall that the interferometric measurement provides only phase values that are ambiguous by integer multiples of $2 \pi$. As a result, the height measurements are also ambiguous by multiples of [7]

$$
h_{\mathrm{amb}}=\frac{\lambda r_{0} \sin \left(\theta_{i}\right)}{B_{\perp}}=\frac{2 \pi}{k_{z}} .
$$

Such ambiguities are usually resolved during phase unwrapping, which exploits spatial correlations between the height values of natural topography [7], [8], [18]. The accuracy of this absolute phase (or height) reconstruction process depends on several factors like the signal-to-noise ratio, the surface and volume decorrelation, the ground resolution, and, most important, the actual terrain itself. The latter may strongly limit the useful baseline length for rough terrain like deep valleys, isolated peaks, tall forests, or mountains with steep slopes. On the other hand, large baselines are desired to achieve a sensitive radar interferometer with a good phase-to-height scaling. This dilemma becomes especially pronounced for future radar sensors, which will provide a high range bandwidth and enable coherent data acquisitions with long interferometric baselines. To illustrate this problem, we choose for the aforementioned satellites just $10 \%$ of the critical baseline. The corresponding baseline lengths vary between several hundred meters for TerraSAR-X and several kilometers for Tandem-L. The spatial decorrelation will be small in this case and can be removed by range filtering [57]. The corresponding heights of ambiguity are shown in Fig. 6 on the right. It becomes clear that the ambiguous heights are rather low in this case, which may cause irresolvable height errors in areas with rough terrain. It is hence in general not possible to take full advantage of the opportunity for large baseline acquisitions in these highbandwidth radar systems.

A solution to this dilemma is an interferometric system with flexible baseline lengths. This enables an adaptation of the baseline to the actual terrain and offers the possibility to image the same area with multiple baselines of different length. The latter can be used for an unambiguous reconstruction of the terrain height (see Section V-A). A natural way to implement such a system is a multistatic radar with multiple spacecraft flying in close formation. Such systems enable adjustable baselines ranging from a few hundred meters up to several kilometers. It allows also an optimization of the baseline to estimate the height of volume scatterers.

\section{Polarimetric SAR Interferometry}

Pol-InSAR applications are based on the evaluation of the complex interferometric coherence that comprises both the interferometric correlation coefficient and the interferometric phase. After calibration for system and processing-induced error contributions, compensation of spectral decorrelation in azimuth and range by spectral filtering [57], and assuming a scatterer reflectivity function that depends in a local neighborhood only on height, the estimated (complex) interferometric coherence can be decomposed into three main decorrelation processes [24], [27], [54]

$$
\gamma:=\gamma_{\mathrm{Temp}} \gamma_{\mathrm{SNR}} \gamma_{\mathrm{Vol}}
$$

- Temporal decorrelation $\gamma_{\text {Temp }}$ can be real or complex and depends on the structure and the temporal stability of the scatterer, the temporal baseline of the interferometric acquisition, and the dynamic environmental processes occurring in the time between the acquisitions.

- Noise decorrelation $\gamma_{\mathrm{SNR}}$ introduced by the additive white noise contribution on the received signal that affects primarily scatterers with low (back-) scattering.

- Volume decorrelation $\gamma_{\mathrm{Vol}}$ is the decorrelation caused by the different projection of the vertical component of the scatterer into the two interferometric images. $\gamma_{\mathrm{Vol}}$ is directly linked to the vertical distribution of scatterers $F(z)$ through a normalized Fourier transform like relationship [27], [38], [54]

$$
\gamma_{\text {Vol }}=\exp \left(i k_{z} z_{0}\right) \frac{\int_{0}^{h_{V}} F\left(z^{\prime}\right) \exp \left(i k_{z} z^{\prime}\right) d z^{\prime}}{\int_{0}^{h_{V}} F\left(z^{\prime}\right) d z^{\prime}}
$$

where $h_{\mathrm{v}}$ is the height of the volume, $z_{0}$ a reference height, and $\phi_{0}=k_{z} z_{0}$ the corresponding interferometric phase. Accordingly, $\gamma_{V o l}$ contains the information about the vertical structure of the scatterer and is therefore the key observable for quantitative forest parameter estimation.

The estimation of vertical forest structure parameters from interferometric measurements can be addressed either by using a model-based parameterization of $F(z)$ [38]-[40], [58] or by expressing $F(z)$ in a functional basis set [59], [60]. In both cases, an extended interferometric observation space is required: in the first case, (fully) polarimetric diversity is required to decompose volume from ground scattering components; while in the second case, (fully) polarimetric diversity combined with multiple baseline acquisitions allow one to obtain vertical resolution. 


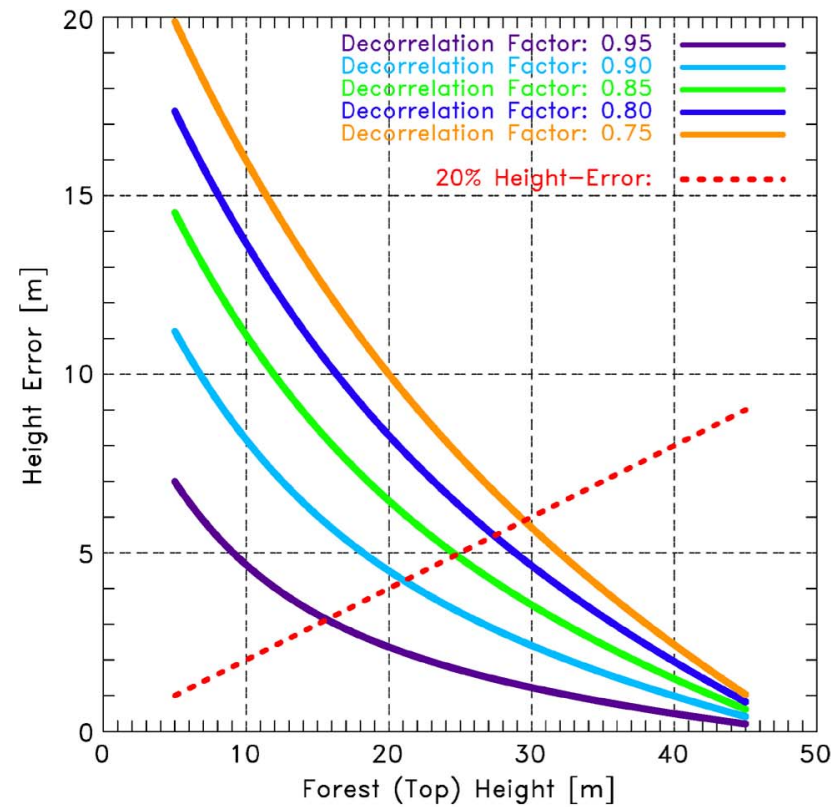

(a)

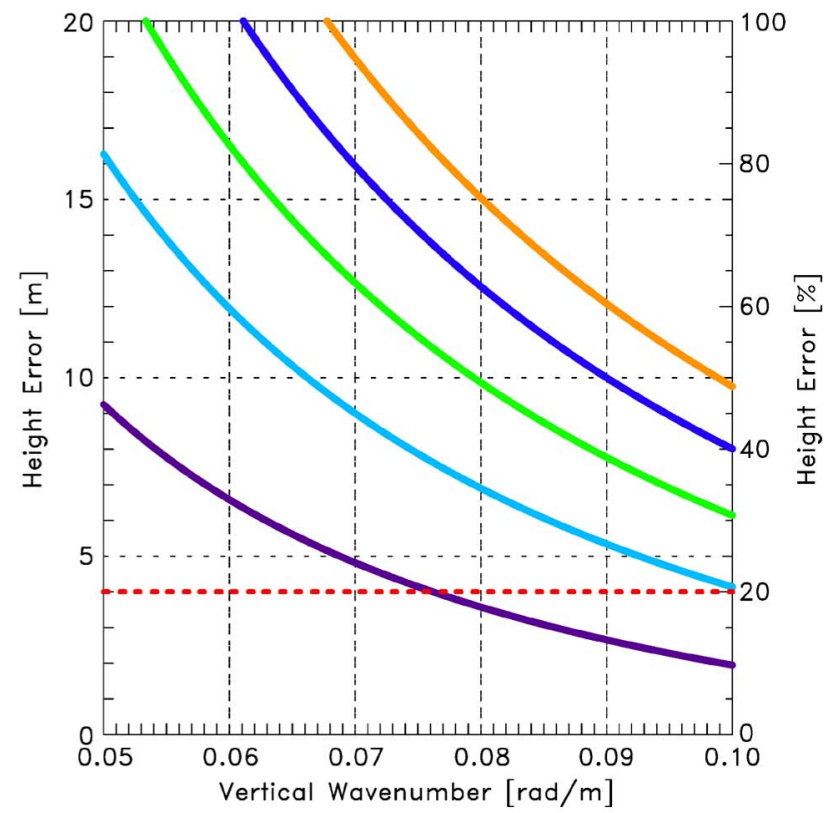

(b)

Fig. 7. (a) Height error induced by different levels of temporal decorrelation as a function of forest height assuming a vertical wavenumber of $k_{\mathrm{z}}=0.1 \mathrm{rad} / \mathrm{m}$. (b) Height error induced by different levels of temporal decorrelation as a function of vertical wavenumber assuming a constant forest height of $20 \mathrm{~m}$.

Equation (7) accounts only for the volume decorrelation contribution of the interferometric coherence while other decorrelation effects are ignored. Such decorrelation contributions reduce the interferometric coherence and increase the variation of the interferometric phase. One of the most prominent decorrelation contributions in the case of nonsimultaneous acquisitions is temporal decorrelation caused by dynamic changes within the scene occurring in the time between the two acquisitions. The inversion of Pol-InSAR coherences contaminated by temporal decorrelation leads to overestimated forest height retrievals. Fig. 7(a) shows the height error obtained for different levels of temporal decorrelation $\left(\left|\gamma_{\text {Temp }}\right|=0.95\right.$ to 0.75 ) as a function of forest height for a vertical wavenumber of $k_{\mathrm{z}}=0.1 \mathrm{rad} / \mathrm{m}$. Clearly, one can see that the estimation errors induced by a constant level of temporal decorrelation are significantly higher for short than for tall heights and that the errors increase with increasing temporal decorrelation. Note that even for low temporal decorrelation levels (on the order of 0.9), the height error is critical for low forest heights. Fig. 7 on the right shows the height error obtained by inverting (7) for different levels of temporal decorrelation $\left(\left|\gamma_{\text {Temp }}\right|=0.90\right.$ to 0.75$)$ as a function of vertical wavenumber assuming a constant forest height of $20 \mathrm{~m}$. Even for low temporal decorrelation levels (on the order of 0.9 ), the height error is critical at small baselines $\left(80 \%\right.$ for $\left.k_{\mathrm{z}}=0.05\right)$ but decreases with increasing baseline lengths: for the same level of temporal decorrelation, the height error decreases to $20 \%$ for a vertical wavenumber of $0.1 \mathrm{rad} / \mathrm{m}$. This makes clear that larger spatial baselines are advantageous in the presence of weak to moderate temporal decorrelation as they minimize the introduced bias by increasing the temporal baseline. The price to be paid is a lower overall coherence leveldue to the increased volume decorrelation contributionthat causes an increased phase variance. This can be compensated by multilooking on the expense of spatial resolution. It becomes clear that for achieving accurate height estimates, the minimization of temporal decorrelation and the availability of multiple and variable baselines is essential.

\section{TanDEM-X MISSION}

TanDEM-X (TerraSAR-X add-on for Digital Elevation Measurement) is an innovative spaceborne radar interferometer mission that will be launched in spring 2010. The primary objective of the TanDEM-X mission is the generation of a worldwide, consistent, timely, and high precision digital elevation model aligned with the HRTI-3 (High Resolution Terrain Information; see Table 1) specification as the basis for a wide range of scientific research, as well as for commercial DEM production [53]. This goal will

${ }^{1}$ The National Geospatial-Intelligence Agency plans to replace the HRTI specification by the High Resolution Elevation standard. Since the TanDEM-X product definition has been closely aligned with the former HRTI definitions, we keep this term for the context of this paper. 
be achieved by means of a second, TerraSAR-X-like satellite flying in close orbit configuration with TerraSAR-X. Both satellites will then act as a large single-pass SAR interferometer with the opportunity for flexible baseline selection. This enables the acquisition of highly accurate cross-track and along-track interferograms without the inherent accuracy limitations imposed by repeat-pass interferometry due to temporal decorrelation and atmospheric disturbances. Besides the primary goal of the mission, several secondary mission objectives based on along-track interferometry as well as new techniques with bistatic SAR have been defined, which represent an important and innovative asset of the mission.

\section{A. TerraSAR-X}

TerraSAR-X, as an essential basis for TanDEM-X, is Germany's first national remote sensing satellite that has been realized in a public private partnership between DLR and industry [55]. The high-resolution SAR satellite, which was successfully launched on June 15, 2007, supplies highquality radar images for scientific and commercial applications for at least five years. TerraSAR-X is the fruit of consistent development of German radar technology over many years and is an example of successful cooperation with the German aerospace industry.

TerraSAR-X is an advanced X-Band radar satellite with a phased array antenna consisting of 384 transmit and receive modules [56]. The antenna is fixed mounted to the spacecraft body and spans an overall aperture size of $4.8 \times 0.7 \mathrm{~m}$. The center frequency of the radar instrument is $9.65 \mathrm{GHz}$ with a selectable range bandwidth of up to $300 \mathrm{MHz}$. Variable antenna beams and multiple operation modes can be selected like Stripmap (3 m resolution, $30 \mathrm{~km}$ swath width), ScanSAR (16 m, $100 \mathrm{~km}$ swath width), or the new high-resolution $(1 \mathrm{~m}, 5-10 \times 10 \mathrm{~km}$ image size) Spotlight mode. The imaging modes can be further combined with different polarization settings. For example, besides the standard single-polarization products $\mathrm{HH}$ and $\mathrm{VV}$, the dual-polarization products $\mathrm{HH}-\mathrm{VV}, \mathrm{HH}-\mathrm{HV}$, and VV-VH as well as experimental quad polarization products can be acquired in strip map mode. Hundreds of beams had to be calibrated during the commissioning phase in order to achieve the specified measurement accuracy. It has been demonstrated that the calibration accuracy of the radar images is better than $0.5 \mathrm{~dB}$ and that the localization accuracy is on the order of half a meter. The space segment for TerraSAR-X has been developed by EADS Astrium in Friedrichshafen and the complete ground segment has been developed by DLR in Oberpfaffenhofen.

Fig. 8 shows a TerraSAR-X image example of the Wadden Sea in North Germany. It consists of an overlay of three images acquired on different days (October 22, 24, and 27, 2007). Changes that occurred between the acquisitions due to tidal variations are shown in blue and green colors. The high localization accuracy of the TerraSAR-X

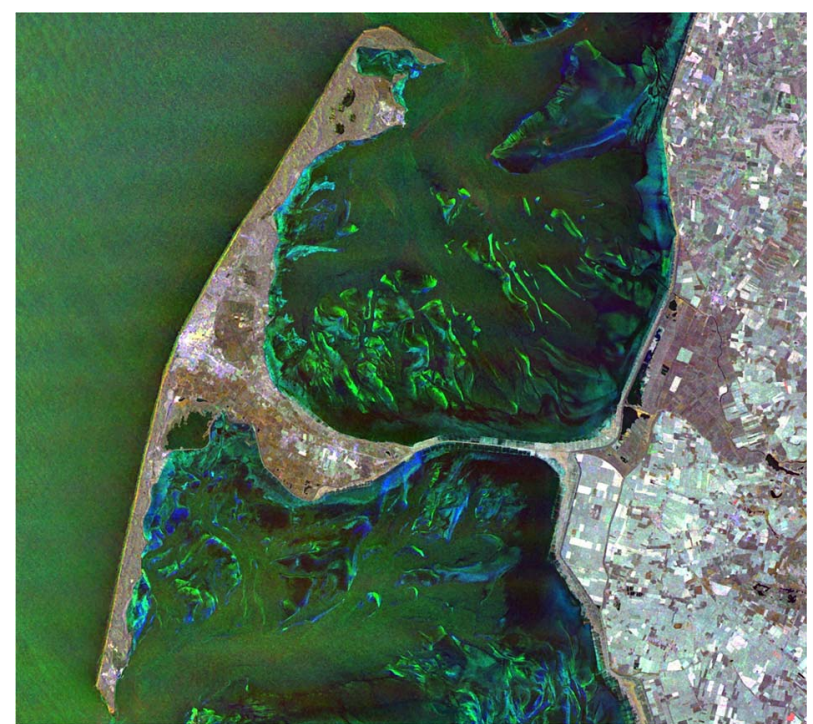

Fig. 8. TerraSAR-X image overlay in ScanSAR mode consisting of three images acquired on October 22 (green), 24 (b/ue), and 27 (red), 2007. The image shows the Sylt Island located in the Wadden Sea, North Germany. Variations in color are due to the tidal changes between the acquisitions.

images is a first for spaceborne radar systems. It is facilitating the image processing in case of multiple acquisitions and supporting the development of a number of applications like glacier velocity estimation, change detection, or deformation mapping using repeat-pass interferometry.

\section{B. Mission Implementation Concept}

The TanDEM-X mission is an extension of the TerraSAR-X mission, coflying a second satellite of nearly identical capability in a close formation. The TerraSAR-X satellite (TSX) has already built in all necessary features required for the implementation of the TanDEM-X mission. Examples are additional X-band horn antennas for intersatellite phase synchronization, the availability of a dual-frequency GPS receiver for precise orbit determination, excellent RF phase stability of the SAR instrument, and PRF synchronization based on GPS as a common time reference. The second satellite (TDX) is a rebuild of TSX with only minor modifications, like an additional cold gas propulsion system required for formation fine-tuning and an additional S-band receiver to enable the reception of status and GPS position information broadcasted by TSX. This guarantees low development risk and offers at the same time the possibility for a flexible share of operational functions among the two satellites. The TDX satellite is designed for a nominal lifetime of $51 / 2$ years and has a nominal operation overlap with TSX of three years. Note in this context that TSX holds consumables and resources for up to seven years of operation, allowing for a potential prolongation of the overlap and the TanDEM-X mission 


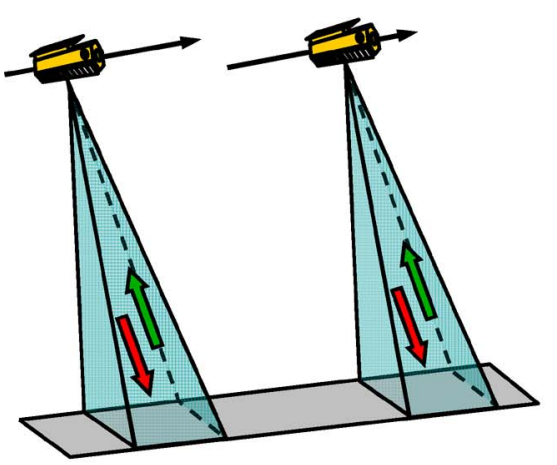

(a)

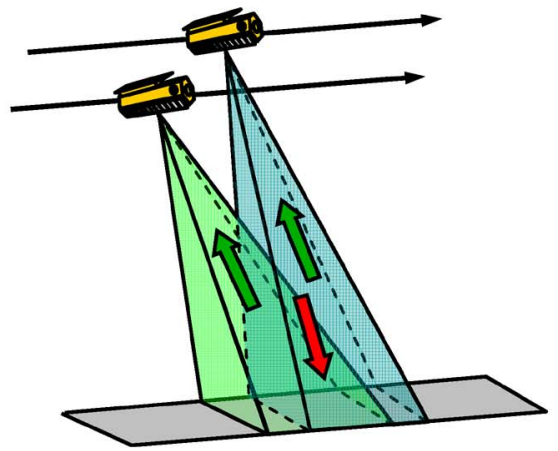

(b)

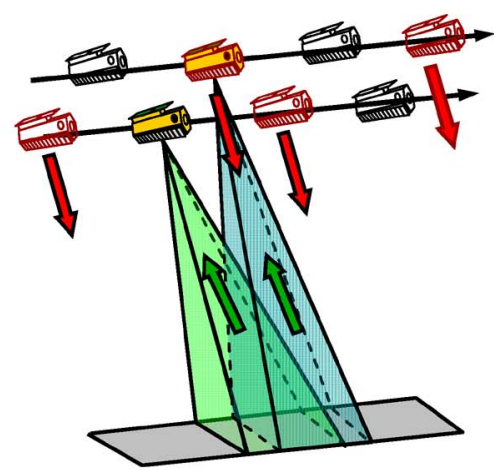

(c)

Fig. 9. Data acquisition modes for TanDEM-X: (a) pursuit monostatic mode, (b) bistatic mode, and (c) alternating bistatic mode.

duration. Like TerraSAR-X, TanDEM-X is implemented in the framework of a public private partnership between the German Aerospace Center (DLR) and EADS Astrium $\mathrm{GmbH}$.

\section{Interferometric Data Acquisition}

Interferometric data acquisition with the TanDEM-X satellite formation can be achieved in three different modes: bistatic, monostatic, and alternating bistatic (see Fig. 9). The three interferometric modes can be further combined with different TSX and TDX SAR imaging modes like Stripmap, ScanSAR, and Spotlight.

Operational DEM generation is planned to be performed using the bistatic InSAR mode shown in Fig. 9(b). This mode uses either TSX or TDX as a transmitter to illuminate a common radar footprint on the Earth's surface. The scattered signal is then recorded by both satellites simultaneously. This simultaneous data acquisition makes dual use of the available transmit power and is mandatory to avoid possible errors from temporal decorrelation and atmospheric disturbances. An essential requirement for radar interferometry on natural surfaces is a sufficient overlap of the two recorded Doppler spectra. In bistatic mode, the two Doppler spectra are mutually shifted, and the amount of this shift is linearly related to the along-track displacement between TSX and TDX. The maximum along-track separation in bistatic stripmap mode should therefore always stay below $1 \mathrm{~km}$, which ensures a sufficient overlap of the Doppler spectra. In addition, PRF synchronization and relative phase referencing between the two satellites are mandatory in the bistatic DEM generation mode.

\section{Relative Phase Referencing}

A peculiarity of the bistatic data acquisition is the use of independent oscillators for modulation and demodulation of the radar pulses. Any deviation between the two oscillators will hence cause a residual modulation of the recorded azimuth signal. The impact of oscillator phase noise in bistatic SAR has been analyzed in [61], where it is shown that oscillator noise may cause significant errors in both the interferometric phase and SAR focusing. The stringent requirements for interferometric phase stability in the bistatic mode will hence require an appropriate relative phase referencing between the two SAR instruments or, as an alternative, an operation in the alternating bistatic mode where the simultaneous acquisition of monostatic and bistatic interferograms allows for synchronization via the common illuminated footprint.

For TanDEM-X, a dedicated intersatellite X-band synchronization link will be established by a mutual exchange of radar pulses between the two satellites. For this, the nominal bistatic SAR data acquisition is shortly interrupted, and a radar pulse is redirected from the main SAR antenna to one of six dedicated synchronization horn antennas mounted on each spacecraft [see Fig. 10(a)]. The pulse is then recorded by the other satellite, which in turn transmits a short synchronization pulse. By this, a bidirectional link between the two radar instruments is formed, which allows for mutual phase referencing without exact knowledge of the actual distance between the satellites. On ground, a correction signal can then be derived from the recorded synchronization pulses, compensating the oscillator-induced phase errors in the bistatic SAR signal. The performance of such a synchronization link has been investigated in [62]. The righthand side of Fig. 10 shows the predicted standard deviation of the residual phase errors after synchronization as a function of the update frequency of the synchronization signals for different signal-to-noise ratios (SNRs) of the bidirectional link. The actual SNR varies with the distance between the satellites as well as their relative attitude. For the typical DEM data-acquisition mode with baselines below $1 \mathrm{~km}$, the SNR will be on the order of 30 to $40 \mathrm{~dB}$, and it becomes clear that a phase error below $1^{\circ}$ can be achieved for synchronization frequencies of $5 \mathrm{~Hz}$. 


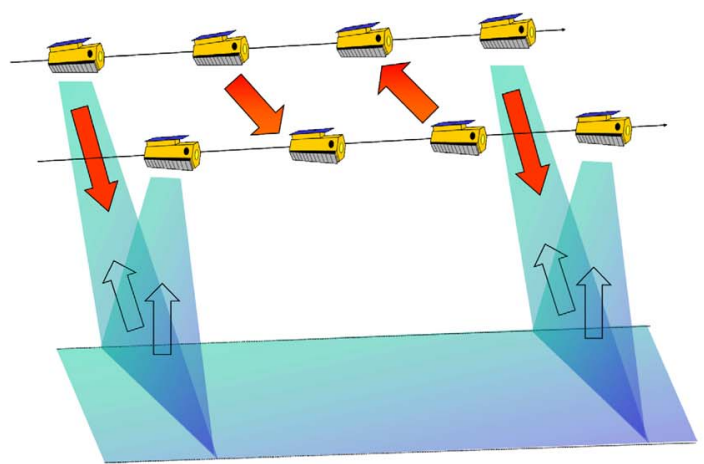

(a)

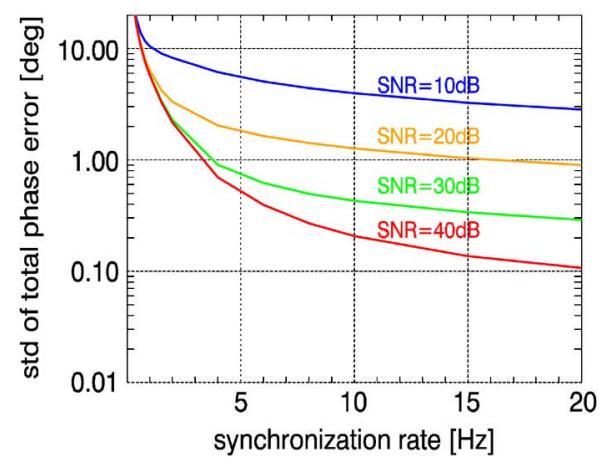

(b)

Fig. 10. Phase synchronization in TanDEM-X. (a) The nominal SAR acquisition is periodically interrupted to exchange radar pulses between the two SAR instruments via dedicated horn antennas. (b) Standard deviation of the total synchronization link phase error as a function of the synchronization frequency. The four curves are for SNRs of $10 \mathrm{~dB}$ (blue), $20 \mathrm{~dB}$ (orange), $30 \mathrm{~dB}$ (green), and $40 \mathrm{~dB}$ (red). The standard deviation of the total phase error should be lower than $1^{\circ}$ to meet the TanDEM-X requirements.

\section{E. Orbit Configuration and Formation Flying}

The TanDEM-X operational scenario requires the coordinated operation of two satellites flying in close formation. The adjustment parameters for the formation are the orbits node line angle, the angle between the perigees, the orbit eccentricities, and the phasing between the satellites [53]. With these parameters, several options have been investigated, and the Helix satellite formation shown in Fig. 11 has finally been selected for operational DEM generation. This formation combines an out-of-plane (horizontal) orbital displacement by different ascending nodes with a radial (vertical) separation by different eccentricity vectors, resulting in a helix-like relative movement of the satellites along the orbit. Since there exists no crossing of the satellite orbits, arbitrary shifts of the satellites along their orbits are allowed. This enables a safe spacecraft operation without the necessity for autonomous control. It is furthermore possible to optimize the alongtrack displacement at predefined latitudes for different applications: cross-track interferometry will aim at alongtrack baselines that are as short as possible to ensure an optimum overlap of the Doppler spectra and to avoid temporal decorrelation in vegetated areas, while other applications like along-track interferometry or superresolution require selectable along-track baselines in the range from a hundred meters to several kilometers. A fine-tuning of the satellite formation will be performed via the aforementioned cold gas propulsion system on TDX.

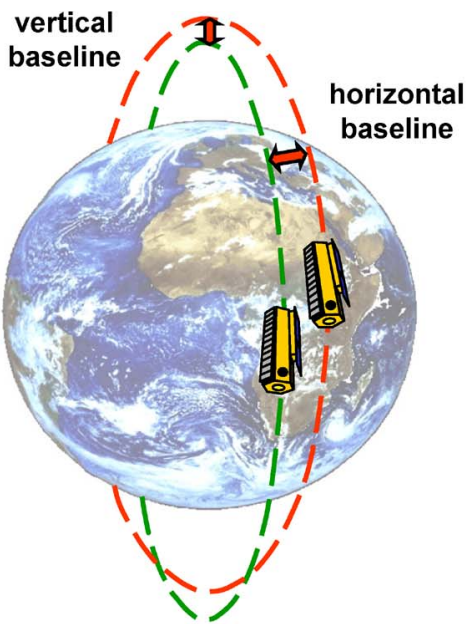

(a)

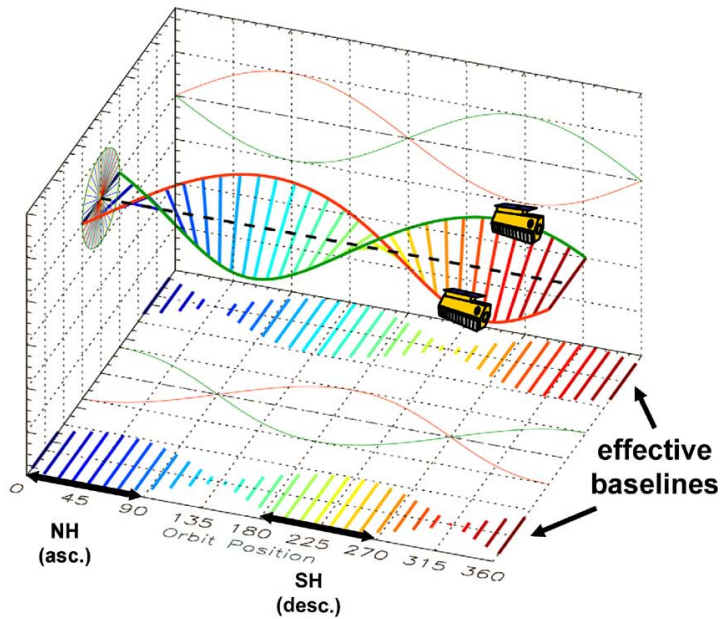

(b)

Fig. 11. Helix satellite formation for TanDEM-X. (a) Orbital arrangement. (b) Cross-track baselines as function of the orbit position. The positions correspond to one complete orbit cycle. 
The Helix formation enables a complete mapping of the Earth with a stable height of ambiguity by using a small number of formation settings [53]. Southern and northern latitudes can be mapped with the same formation by using ascending orbits for one and descending orbits for the other hemisphere, as illustrated in Fig. 11(b). A fine-tuning of the cross-track baselines can be achieved by taking advantage of the natural rotation of the eccentricity vectors due to secular disturbances, also called motion of libration. The phases of this libration can be kept in a fixed relative position with small maneuvers using the cold gas thrusters on a daily basis, while major formation changes as well as a duplication of the orbit keeping maneuvers required by TSX will be performed by the hot gas thrusters.

\section{F. Performance Analysis}

This section investigates the interferometric performance of TanDEM-X. For this, an interferometric data acquisition in bistatic stripmap mode will be assumed. Major factors that affect the relative height accuracy are the radiometric sensitivity of each SAR instrument, range and azimuth ambiguities, quantization noise, processing and coregistration errors as well as surface and volume decorrelation, scaled by the baseline length. The key quantity in estimating the interferometric performance is the coherence that has been computed by the product [9], [24], [54]

$$
\gamma_{\text {tot }}=\gamma_{\mathrm{SNR}} \cdot \gamma_{\mathrm{Quant}} \cdot \gamma_{\mathrm{Amb}} \cdot \gamma_{\mathrm{Coreg}} \cdot \gamma_{\mathrm{Geo}} \cdot \gamma_{\mathrm{Az}} \cdot \gamma_{\mathrm{Vol}} \cdot \gamma_{\mathrm{Temp}}
$$

where the right-hand side describes the different error contributions due to the limited SNR $\left(\gamma_{\mathrm{SNR}}\right)$, quantization $\left(\gamma_{\text {Quant }}\right)$, ambiguities $\left(\gamma_{\mathrm{Amb}}\right)$, limited coregistration accuracy $\left(\gamma_{\text {Coreg }}\right)$, baseline decorrelation $\left(\gamma_{\text {Geo }}\right)$, relative shift of Doppler spectra $\left(\gamma_{\mathrm{Az}}\right)$, volume decorrelation $\left(\gamma_{\mathrm{Vol}}\right)$, and temporal decorrelation $\left(\gamma_{\text {Temp }}\right)$. Each of these terms has been evaluated. Fig. 12 shows the result of the interferometric performance analysis for two different ambiguous heights corresponding to different baseline lengths on the order of 300 and $450 \mathrm{~m}$, respectively. The reader is referred to [53] for a detailed derivation of relative and absolute height errors and an outline of the TanDEM-X dataacquisition plan.

\section{G. Secondary Mission Objectives}

Besides its primary mission objective, TanDEM-X will provide the remote sensing scientific community with a unique data set to demonstrate the capability of new bistatic radar techniques and to apply these innovative techniques for enhanced geo- and biophysical parameter retrieval.

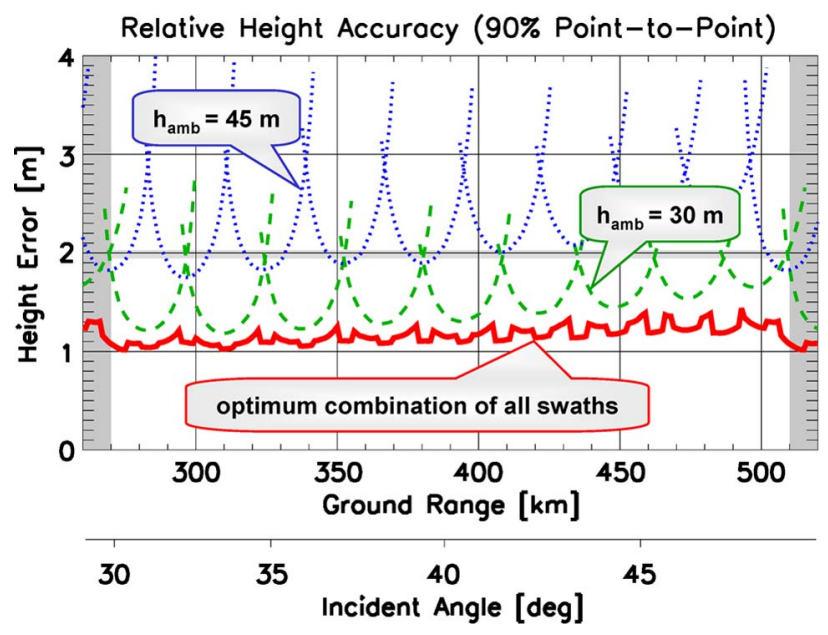

Fig. 12. Height accuracy for a height of ambiguity of 45 (dotted) and $30 \mathrm{~m}$ (dashed). The lower solid curve shows the error resulting from the combination of multiple swaths. All errors are point-to-point height errors for a $12 \mathrm{~m}$ posting and a $90 \%$ confidence interval.

1) Along-Track Interferometry: TanDEM-X is predestined for along-track interferometry (ATI), which compares the phase of two complex SAR images acquired in identical geometries but separated by a short time interval. This technique is well suited for monitoring dynamic processes on the Earth's surface. As outlined in Section III-E, it is possible to adjust the along-track displacement between the two satellites from almost zero to several kilometers. By this, it becomes possible to adapt the ATI sensitivity of TanDEM-X to a wide range of radial velocities. The Helix formation enables even a minimization of the across-track component for a given latitude and incident angle. Alongtrack interferometry can furthermore be performed by the so-called dual-receive antenna mode in each of the two tandem satellites, which provides additional along-track baselines of $2.4 \mathrm{~m} \mathrm{[63].} \mathrm{The} \mathrm{combination} \mathrm{of} \mathrm{short} \mathrm{and} \mathrm{long}$ baseline ATI data acquisitions can be used to improve both the detection and localisation of moving objects and to resolve phase ambiguities from high-velocity scatterers. TanDEM-X provides hence a capable along-track SAR interferometer with four phase centers (see Fig. 13). Potential applications are Ground Moving Target Indication, the measurement of ocean currents, and the monitoring of sea ice drift.

2) Very Large Baseline Cross-Track Interferometry: Very large baseline interferometry takes advantage of the high RF bandwidth of the TSX and TDX satellites, which allows for coherent data acquisitions with baselines of up to $5 \mathrm{~km}$ and more. Note that less than $5 \%$ of the maximum possible (critical) baseline length is used during nominal DEM data acquisition. Large baseline interferograms can hence significantly improve the height accuracy, but the associated low height of ambiguity requires a combination of multiple 


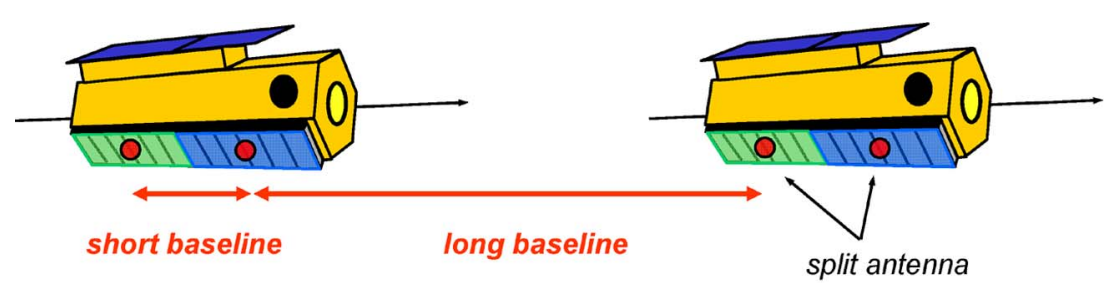

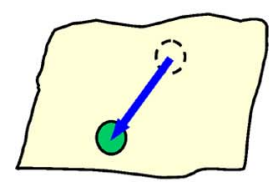

sensitive to fast movements

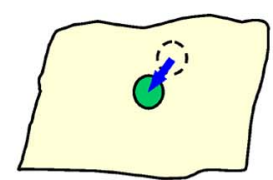

sensitive to slow movements

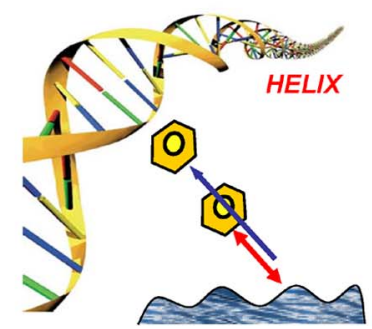

Fig. 13. Along-track interferometry with TanDEM-X. The Helix orbit concept allows a flexible adjustment of the desired along-track separation between the satellites. In addition, a short along-track baseline is provided by each satellite.

interferograms with different baseline lengths to resolve phase ambiguities. By this, it becomes possible to derive DEMs with HRTI-4-like accuracy on a local or even regional scale. Further opportunities arise from a comparison of multiple large baseline TanDEM-X interferograms acquired during different passes of the satellite formation. This provides a very sensitive measure for vertical scene and structure changes with a height sensitivity of a few decimeters. Potential applications are a detection of the grounding line that separates the shelf from the inland ice in polar regions, monitoring of vegetation growth, mapping of atmospheric water vapor with high spatial resolution, measurement of snow accumulation, or the detection of anthropogenic changes of the environment, e.g., due to deforestation. Note that most of these combinations rely on a comparison of two or more single-pass (large baseline) cross-track interferograms and do hence not necessarily require coherence between the different passes, i.e., the highly accurate measurement of the height change is not affected by temporal decorrelation. Further information can be gained from an evaluation of coherence changes (e.g., from varying volume decorrelation) between different passes, potentially augmented by polarimetric information. This could, for instance, reveal even slight changes in the soil and vegetation structure reflecting vegetation growth and loss, freezing and thawing, fire destruction, human activities, and so on. TanDEM-X hence enables the entry into a new era of interferometric (and tomographic) processing techniques as did ERS-1/2 for the development of classical repeat-pass SAR interferometry.

3) Polarimetric SAR Interferometry: Pol-InSAR combines interferometric with polarimetric measurements to gain additional information from semitransparent volume scatterers [32]. This allows, e.g., for the extraction of important biophysical parameters like vegetation density and vegetation height. Fully polarimetric operation in TanDEM-X uses the split antenna and is susceptible to

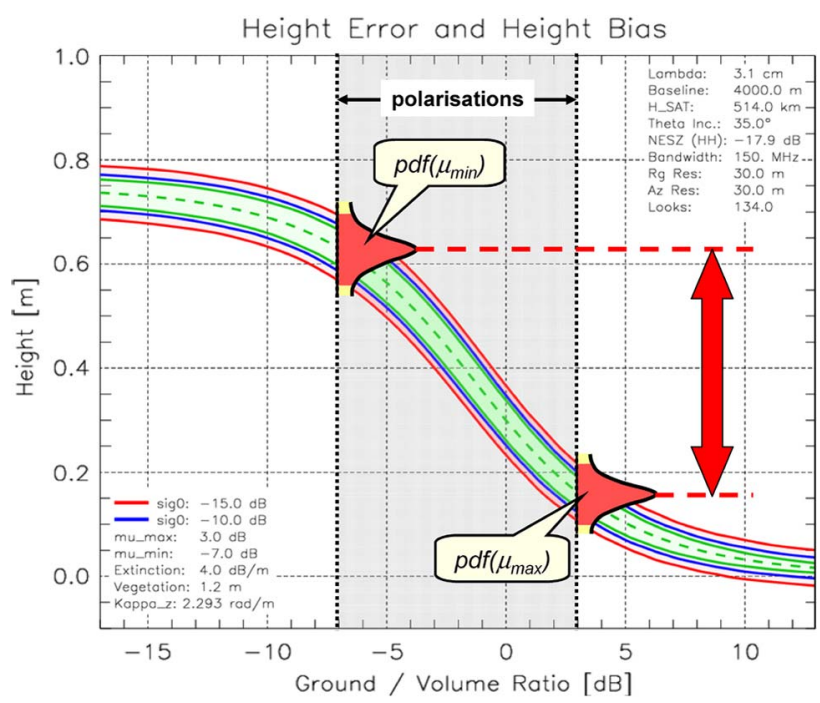

Fig. 14. Variation of the interferometric phase center heights in TANDEM-X as a function of the ground-to-volume scattering ratio $\mu$ (see [64]). Different values of $\mu$ correspond to different polarizations. The green tube indicates the errors from volume decorrelation. The blue and red tubes show additional height errors due to the limited SNR for scattering coefficients of -10 and -15 dB, respectively. The red arrow illustrates that the vertical phase center locations for minimum and maximum $\mu$ are well separated if compared to the height uncertainty indicated by the height error pdfs for $\mu_{\min }$ and $\mu_{\max }$. The assumed vegetation height in this height error prediction is $1.2 \mathrm{~m}$, the ground-to-volume ratio $\mu$ is assumed to vary between -7 and $+3 \mathrm{~dB}$ for the different polarizations, and the extinction is assumed to be $4 \mathrm{~dB} / \mathrm{m}$. 
ambiguities. This can be avoided by reducing the processed azimuth bandwidth and/or by limiting the swath width.

Fig. 14 illustrates the achievable performance of a simulated scenario for TanDEM-X. This analysis is based on the Random Volume over Ground (RVoG) model [16] assuming a vegetation layer with a height of $1.2 \mathrm{~m}$ and an extinction coefficient of the radar waves in vegetation of $4 \mathrm{~dB} / \mathrm{m}$. The dashed line indicates the height variation of the interferometric phase center with different polarizations (corresponding to a variation of the ground-tovolume ratio on the abscissa). The green tube shows the height errors due to volume decorrelation for an effective baseline of $4 \mathrm{~km}$ and an independent postspacing of $30 \times$ $30 \mathrm{~m}^{2}$. The blue and red tubes show the effect of additional noise-like errors due to the limited system sensitivity for scattering coefficients of -10 and $-15 \mathrm{~dB}$, respectively. The performance analysis predicts a sufficient phase center separation to enable a successful retrieval of important vegetation parameters like volume height, extinction, etc. TanDEM-X will be the first mission to demonstrate this technique in a single-pass data acquisition mode from space.

4) Bistatic SAR Imaging: Bistatic SAR imaging provides additional observables for the extraction of important scene and target parameters [65]. TanDEM-X allows for the simultaneous acquisition of bistatic and monostatic images in a single data take to obtain a highly informative set of multiangle observations. A quantitative evaluation of the bistatic radar cross-section and a comparison with its monostatic equivalents facilitates the detection and recognition of targets. The segmentation and classification in radar images is expected to be substantially improved by comparing the spatial statistics of mono- and bistatic scattering coefficients. This is also supported by the results from an airborne bistatic radar campaign performed in close collaboration between DLR and ONERA [66]. This joint experiment, which was conducted in early 2003 in Southern France, revealed significant changes of the scattering behavior for both artificial and natural targets even in case of rather small bistatic angles [67]. A joint evaluation of mono- and bistatic SAR images could furthermore be used to isolate different scattering mechanisms like, e.g., a distinction between highly directive dihedral returns from more isotropic volume scattering. Bistatic SAR imaging has moreover potential for the retrieval of sea state parameters, the estimation of surface roughness and terrain slope, as well as stereogrammetric, meteorological, and atmospheric applications [68]. Innovative processing algorithms will be required to exploit all these capabilities. The bistatic data acquired with TanDEM-X will hence provide a unique data source to improve our understanding of bistatic imaging and its exploitation for future remote sensing applications. Data takes with large bistatic angles are planned at the begin- ning and the end of the TanDEM-X mission where the satellites are separated from each other by several tenths of kilometers.

5) Digital Beamforming and Super Resolution: Digital beamforming combines the RF signals from a set of small nondirectional antennas to simulate a large directional antenna. Due to the split antennas and dual receiver channels of TSX and TDX, four phase centers can be obtained with TanDEM-X. An appropriate combination of the multiple receive signals enables then an efficient suppression of azimuth ambiguities [69]. By this, it is possible to demonstrate the capabilities of a highresolution wide swath SAR imaging. This technique is also of interest for advanced interferometric SAR modes like the alternating bistatic mode where it allows for a reduction of the PRF, thereby resolving potential timing and ambiguity conflicts. TanDEM-X will be the first configuration that demonstrates this highly innovative technique from space.

Another promising technique is superresolution. This technique exploits the fact that the signals received by the two satellites have different aspect angles for each scattering point on the ground. In consequence, the two ground range and/or azimuth spectra are shifted relative to each other [57]. A coherent combination of the signals yields then a wider spectrum, which corresponds to an improved spatial resolution. This technique requires a cross-track and/or along-track separation in the order of 5-10 km. Such baselines will be available in later mission phases after the standard DEM data acquisition has been completed.

\section{TANDEM-L MISSION PROPOSAL}

Tandem-L is a proposal for an innovative interferometric radar mission to monitor the Earth system and its intricate dynamics (see Fig. 15). Important mission objectives are global inventories of 3-D forest structure and above-ground biomass; large-scale measurements of Earth surface deformations due to plate tectonics, erosion, and anthropogenic activities; observations of glacier movements and 3-D structure changes in land and sea ice; and monitoring of ocean surface currents. Similar to TanDEM-X, the Tandem-L mission concept is based on coflying two SAR satellites in a close formation. The synergistic use of two fully polarimetric L-band radar satellites enables highly accurate interferometric and polarimetric measurements to derive contiguous 3-D structure profiles and their spatiotemporal evolution. The advanced imaging capabilities and the systematic data acquisition strategy make Tandem-L a unique observatory to significantly advance our scientific understanding of environmental processes in the bio-, geo-, cryo-, and hydrosphere. A detailed description of the mission goals can be found in [70]. The German Tandem-L mission proposal has in its primary science objectives 


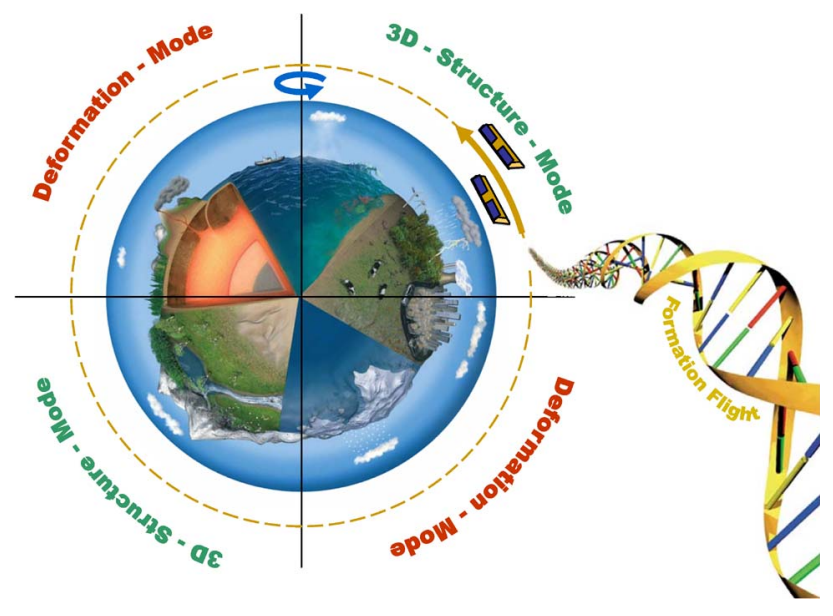

Fig. 15. The Tandem-L mission concept relies on a systematic data-acquisition strategy using a pair of L-band SAR satellites flying in close formation. The satellite system is operated in two basic data-acquisition modes: 3-D structure mode and deformation mode. New SAR imaging techniques enable frequent coverage with high geometric resolution.

several commonalities with the DESDynI mission [71] suggested by the U.S. National Research Council in its Decadal Survey for Earth Science. DLR and NASA/JPL are currently investigating in the scope of a prephase A study the feasibility of a joint mission that meets or even exceeds the science requirements of both proposals and provides at the same time a significant cost reduction for each partner.

Tandem-L is proposed to employ many innovative techniques and technologies to achieve its ambitious mission goals. One example is the use of advanced digital beamforming techniques to provide a wide swath coverage and short revisit times without compromising fine geometric resolution. This innovation enables a frequent monitoring of two-dimensional (2-D) and 3-D structure changes with high precision. The systematic acquisition of wide-area single-pass and repeat-pass interferograms with high revisit frequency will open a new era in radar remote sensing. It can be expected that besides the primary mission objectives, a wealth of new applications will emerge from the unique Tandem-L observatory. The following sections give an overview of the Tandem-L mission concept. Special emphasis is put on the innovative SAR imaging techniques.

\section{A. Science Requirements}

The science requirements for Tandem-L have been elaborated and repeatedly refined during several international workshops that brought together representatives from multiple geoscience disciplines. It turned out that Tandem-L has exceptional capabilities to acquire a worldwide unique data set that enables a wealth of innovative remote sensing applications and provides fundamental information to resolve urgent scientific questions related to climate research, geophysics, hydrology, glaciology, and vegetation monitoring. Leading scientists specified the observational requirements of their respective disciplines. The top level Tandem-L mission goals can be grouped by the following target areas.

1) Biosphere: Twenty-six percent of the land surfaces are covered with forest corresponding to an area of 40 Mio $\mathrm{km}^{2}$. Forests play an important role in storing natural resources (ecological and economical aspect) and carbon (climate aspect). The relation between carbon content and biomass is given by the dry matter of the wood; $50 \%$ of the plant dry matter consists of carbon. The role of biomass in the global carbon cycle is determined by two components: the static and the dynamic. The static describes the amount of biomass currently existing worldwide. The dynamic is defined through the biomass change occurring due to forest structure change or forest areas extent change. Accurate estimation of the amount and the spatial distribution of both components is essential for the quantification of the carbon fluxes associated to land-use change and the residual terrestrial sink that are today the most unknown contributions within the global carbon cycle budget. Tandem-L will be the first mission that measures biomass with an accuracy of $20 \%$ on a global scale and in addition estimates its yearly change throughout the mission lifetime. With this information, the uncertainty in the terrestrial stored above-ground biomass will be drastically reduced. Biomass will be derived from the measurement of forest height and 3-D forest structure. The main requirements from the biosphere science team can be summarized with the following global goals:

- measurement of forest height and structure;

- global inventory of above-ground forest biomass;

- detecting vegetation disturbances and biomass changes.

2) Geosphere: The topography of the solid Earth is continuously changing due to several processes like continental drift, magma movement on smaller spatial scales, water-level changes, and other processes with anthropogenic influence. The results of these movements may be disastrous events such as earthquakes, volcano eruptions, landslides, or surface up- and down-lifting. The main scientific requirement is to substitute the irregular coarse-mesh grid (provided, e.g., by pointwise GPS measurements) with a homogenous high-resolution deformation map with wide coverage. These accurate deformation maps are on the one side needed for interand coseismic change detection, especially at fault zones; and on the other side they will map worldwide and consistently seismic and volcanic areas with an accuracy and coverage that cannot be achieved with GPS. In addition, small-scale deformation areas like landslides will be detectable due to the high resolution. Not only 
anthropogenic factors like water-level lowering can lead to land slides and deformation. These can also be initiated through climate change where the permafrost soil is thawing. The global science requirements for the geosphere can be summarized as:

- understanding earthquake and volcano eruption cycles;

- quantifying the magnitude of events;

- determination and forecasting the probability of events.

3) Cryo- and Hydrosphere: Processes occurring in the cryo- and hydrosphere are indicators for climate change and have an inevitable impact on the stability of the Earth system. The already observed dramatic changes such as the worldwide melting of the inland glaciers and of the Greenland ice sheets, the thawing of permafrost soils, the diminishing of the Artic sea ice, and so forth are calling considerable attention from the climate science community, national and international policymakers, and the media and general public.

The cryosphere is the largest potential source for sealevel fluctuations and contains $90 \%$ of the Earth's freshwater. The prediction of future sea-level rise is therefore difficult. Estimates of the rise during the twenty-first century vary from 20 to $60 \mathrm{~cm}$ in the IPCC 2007 report, and more recent studies predict even higher values. The consequences range from modest coastlines migration to changes with profound political and economical consequences. The largest uncertainties are associated with the ice sheets, but all sources of sea-level rise require improved regular measurements. In order to monitor parameters that are important for detecting environmental changes affecting the Earth's climate, whereby sea-level fluctuations are only one component, a consistent observation with sufficient temporal and spatial resolution as well as wide coverage is needed.

Hydrology, which is also affected by changes of snow cover and ice extent, contributes also to the understanding of Earth surface processes. Several other current and future missions are dedicated to hydrology and oceanography. Tandem-L with its systematic mapping concept can provide important information about surface soil moisture over the main Earth's agricultural regions. Other contributions are ocean current measurements (close to the shoreline and partly in the deep ocean). The main objective for the cryo- and hydrosphere can be summarized as:

- measurements of ice structure and its changes (including glacier velocity);

- monitoring soil moisture and surface water changes;

- observation of ocean currents and wave field dynamics.

Table 2 provides a short summary of a selected subset of the collected requirements.

\section{B. Mission Concept}

The Tandem-L mission concept relies on a systematic data-acquisition strategy using a pair of co-operating L-band SAR satellites flying in close formation. The satellite system operates in two basic measurement modes (see Fig. 16):

- The 3-D structure mode employs fully polarimetric single-pass SAR interferometry to acquire structural parameters and quasi-tomographic images of semitransparent volume scatterers like vegetation, sand, and ice.

- The deformation mode employs repeat-pass interferometry in an ultrawide swath mode to measure small shifts on the Earth surface with millimetric accuracy and short repetition intervals.

Fig. 17 shows an example of the predicted accuracy of forest height measurements using the Pol-InSAR structure mode [16], [40]. The performance depends on both the forest height and the length of the cross-track baseline (expressed here in terms of the vertical wavenumber $k_{z}$ ). Accuracies below $10 \%$ can be achieved by combining multiple acquisitions with different vertical wavenumbers.

The Tandem-L acquisition plan foresees a systematic variation of the cross-track baselines to optimize forest height and vegetation profile measurements in the 3-D structure mode. At least three acquisitions with vertical wavenumbers $k_{z}$ ranging from 0.05 to $0.2 \mathrm{rad} / \mathrm{m}$ are planned for each season. Fig. 18 shows the correspondence between $k_{z}$ and the lengths of the perpendicular baselines assuming an interferometric acquisition in bistatic mode. For an orbital altitude of $700 \mathrm{~km}$ and incident angles ranging from $30^{\circ}$ to $45^{\circ}$, the required perpendicular baselines vary between $750 \mathrm{~m}$ and $5 \mathrm{~km}$. At the equator, this corresponds to horizontal baselines between $850 \mathrm{~m}$ and $6.6 \mathrm{~km}$ in the case of using a Helix formation with no radial orbit separation at zero latitude.

An elegant technique to provide this wide range of cross-track baselines exploits the naturally occurring differential secular variations of the right ascension of the ascending nodes in response to slightly different inclinations. Fig. 19 shows the evolution of the horizontal baselines at the equator for different inclination offsets. In this figure, the inclination offsets are expressed as horizontal baselines at the northern and southern orbit turns.

A further challenge for Tandem- $\mathrm{L}$ is the adjustment of large cross-track baselines at higher latitudes. One opportunity is the use of a large eccentricity offset to provide a sufficient radial orbit separation at high latitudes, but a significant amount of fuel $^{2}$ will be required to compensate the resulting motion of libration for longer time

\footnotetext{
${ }^{2}$ The required $\Delta \mathrm{v}$ is about $10 \mathrm{~m} / \mathrm{s}$ per kilometer radial baseline for each year. A five-year mission with an average radial baseline of $2 \mathrm{~km}$ would hence require about $5 \%$ of the satellite mass for fuel in case of using a hot gas propulsion system with an exhaustive velocity of $2000 \mathrm{~m} / \mathrm{s}$.
} 
Table 2 Tandem-L User Requirements (Excerpt)

\begin{tabular}{|c|c|c|c|c|}
\hline & Science Product & Coverage & $\begin{array}{c}\text { Product } \\
\text { Resolution }\end{array}$ & $\begin{array}{l}\text { Product } \\
\text { Accuracy }\end{array}$ \\
\hline \multirow{4}{*}{$\frac{\frac{0}{0}}{\frac{0}{0}}$} & Forest Height & \multirow{4}{*}{$\begin{array}{c}\text { all } \\
\text { forest } \\
\text { areas }\end{array}$} & $\begin{array}{c}50 \mathrm{~m} \text { (global) } \\
20 \mathrm{~m} \text { (local) }\end{array}$ & $\sim 10 \%$ \\
\hline & Above Ground Biomass & & $\begin{array}{c}100 \mathrm{~m} \text { (global) } \\
50 \mathrm{~m} \text { (regional) }\end{array}$ & $\begin{array}{c}\sim 20 \% \\
\text { (or } 20 \text { t/ha) }\end{array}$ \\
\hline & Vertical Forest Structure & & $\begin{array}{c}50 \mathrm{~m} \text { (global) } \\
20 \mathrm{~m} \text { (local) }\end{array}$ & 3 layers \\
\hline & Underlying Topography & & $50 \mathrm{~m}$ (horizontal) & $<4$ m (height) \\
\hline \multirow{4}{*}{ 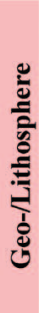 } & Plate Tectonics & $\begin{array}{l}\text { all risk } \\
\text { areas }\end{array}$ & $\begin{array}{l}100 \mathrm{~m} \text { (global) } \\
<20 \mathrm{~m} \text { (fault) }\end{array}$ & $1 \mathrm{~mm} /$ year (after 5 y) \\
\hline & Volcanoes & $\begin{array}{c}\text { all land } \\
\text { volcanoes }\end{array}$ & $20-50 m$ & $5 \mathrm{~mm} /$ week \\
\hline & Landslides & risk areas & $5-20 m$ & $5 \mathrm{~mm} /$ week \\
\hline & Subsidence & urban areas & $5-20 \mathrm{~m}$ & $1 \mathrm{~mm} /$ year \\
\hline \multirow{6}{*}{ 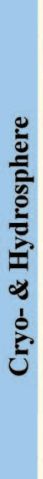 } & Glacier Flow & $\begin{array}{l}\text { main } \\
\text { glaciers }\end{array}$ & $100-500 \mathrm{~m}$ & $5-50 \mathrm{~m} /$ year \\
\hline & Soil Moisture & selected areas & $50 \mathrm{~m}$ & $5-10 \%$ \\
\hline & Water Level Change & regional & $50 \mathrm{~m}$ & $10 \mathrm{~cm}$ \\
\hline & Snow Water Equivalent & local (exp.) & $100-500 \mathrm{~m}$ & $10-20 \%$ \\
\hline & Ice Structure Changes & local (exp.) & $100 \mathrm{~m}$ & $>1$ layer \\
\hline & Ocean Currents & prio. areas & $\sim 100 \mathrm{~m}$ & $<1 \mathrm{~m} / \mathrm{s}$ \\
\hline$\equiv$ & $\begin{array}{l}\text { Digital Terrain } \& \\
\text { Surface Model }\end{array}$ & Global & $\begin{array}{c}\sim 20 \mathrm{~m} \text { (bare) } \\
\sim 50 \mathrm{~m} \text { (forest) }\end{array}$ & $\begin{array}{l}2 \mathrm{~m} \text { (bare) } \\
4 \mathrm{~m} \text { (veg.) }\end{array}$ \\
\hline
\end{tabular}

periods. Another opportunity is the use of an even larger separation of the ascending nodes, which may then provide sufficient baselines for accurate forest height retrievals in the mid-latitudes. Boreal forests at higher latitudes can moreover be imaged in the alternating bistatic mode, which doubles the phase-to-height scaling, thereby increasing the effective baseline by a factor of two. An optimized data-acquisition concept is currently under development.

Fig. 20 shows the predicted accuracy of onedimensional line-of-sight displacements in the deformation mode. Here, a linear deformation model with parameters provided in the figure caption has been assumed. It becomes clear that, for a large number of images, contributions from SNR decorrelation can be neglected while temporal decorrelation and atmospheric phase errors become the main limiting factors. Errors from temporal decorrelation can be reduced by increasing the number of independent looks, while the highly correlated atmo- spheric errors ask for an increased number of acquisitions. ${ }^{3}$ A large number of high-resolution SAR images will be necessary to achieve the desired accuracy of $1 \mathrm{~mm} / \mathrm{y}$ after a five- to seven-year mission time. Two- and 3-D deformation measurements require in addition observations from different incident angles as well as ascending and descending orbits. Tandem-L improves the deformation measurements via innovative SAR modes that enable frequent coverage with high geometric resolution.

The repeat-pass deformation measurements will moreover benefit from the opportunity to simultaneously acquire single-pass cross-track interferograms. The additional information can be used to accurately remove the topographic phase signature arising from repeat orbits with nonvanishing cross-track separations [19]. This reduces the requirements on the orbit control accuracy and therefore

\footnotetext{
${ }^{3}$ Contributions from the ionosphere can also be reduced by advanced calibration techniques while contributions from the troposphere could be reduced and/or filtered via external (e.g., meteorological) information.
} 


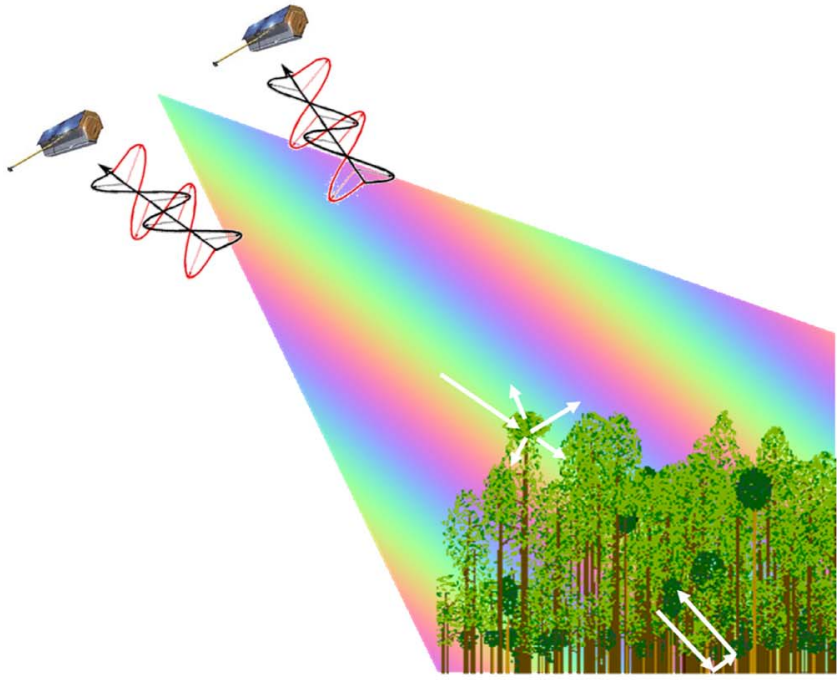

(a)

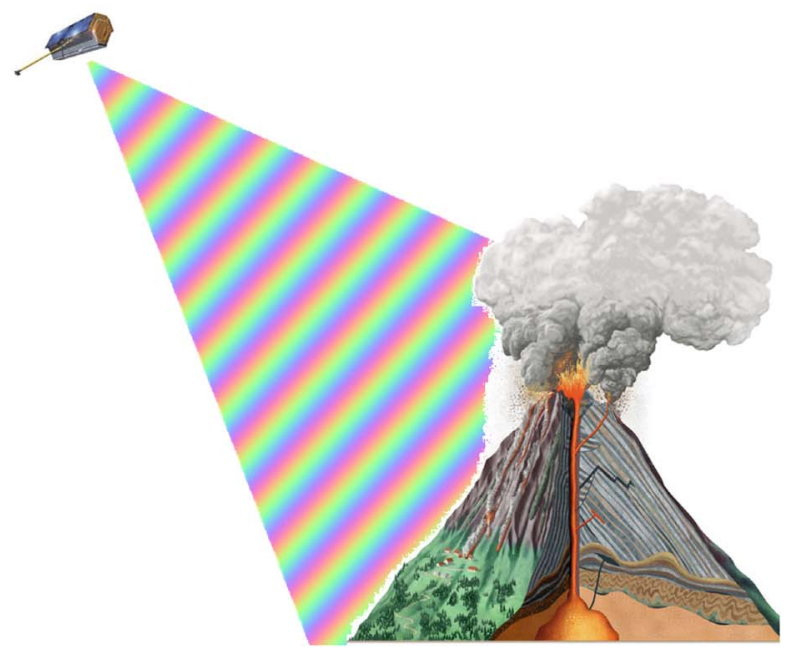

(b)

Fig. 16. Measurement modes of Tandem-L. (a) The 3-D structure mode employs polarimetric SAR interferometry to measure tree heights and vertical vegetation profiles. The individual contributions from ground and canopy are separated via their polarimetric signatures, and the corresponding heights are measured by cross-track interferometry. (b) The deformation mode employs repeat-pass interferometry to measure range changes with millimetric accuracy.

fuel consumption in the satellites. Further opportunities are the resolution of velocity ambiguities for fast deformations, the mitigation of tropospheric and ionospheric phase errors by a joint evaluation of the multiple single-pass and repeat-pass SAR interferograms, the improved detection and classification of deterministic scatterers, and the separation of signals affected by layover.

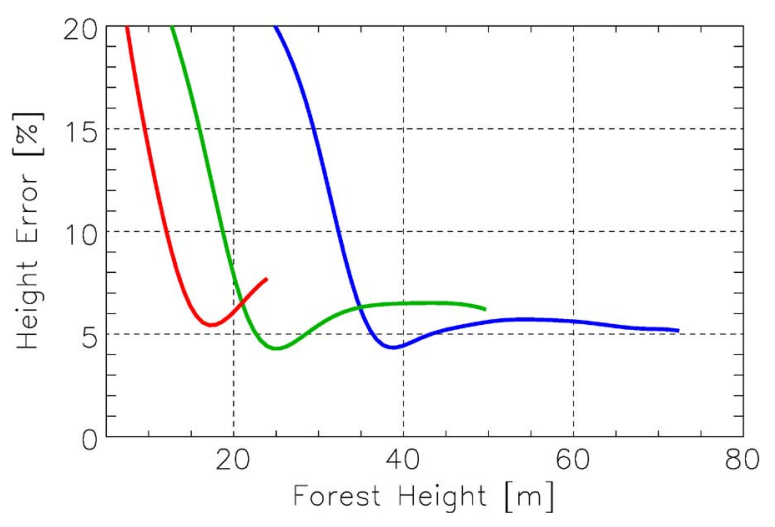

Fig. 17. Performance prediction example for the 3-D structure mode. The colored curves show the expected accuracy of vegetation height measurements for different vertical wavenumbers (blue: $k_{\mathrm{z}}=0.05 \mathrm{rad} / \mathrm{m}$, green: $k_{\mathrm{z}}=0.1 \mathrm{rad} / \mathrm{m}$, red: $\mathrm{k}_{\mathrm{z}}=0.2 \mathrm{rad} / \mathrm{m}$ ) and $n=30$ looks. An RVoG model has been assumed with an extinction of $0.3 \mathrm{~dB} / \mathrm{m}$. System errors (mainly from limited SNR) have been modeled by a decorrelation factor of $\gamma_{\mathrm{sys}}=0.9$. The domain of the individual curves is limited to those forest heights that can be measured without ambiguities.

\section{SAR Instrument Innovation}

A challenge for Tandem- $\mathrm{L}$ is the development of costeffective and at the same time powerful SAR satellites that meet the high demands from the science requirements. The achievement of this goal requires new ideas, concepts, and technologies. A key innovation in Tandem-L will be a shift of the digital interface towards the radar antenna allowing for digital beamforming. The software controlled generation of multiple and highly adaptive antenna beams enables novel and extremely powerful SAR imaging modes that can be optimally adapted to the different user requirements.

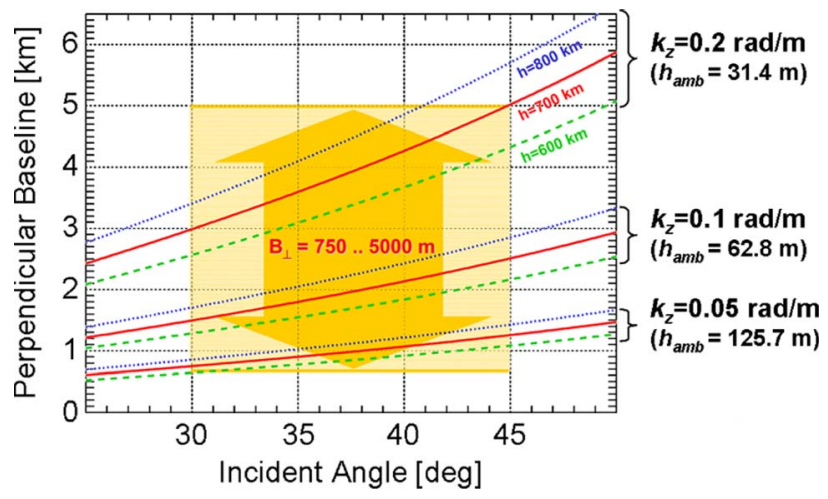

Fig. 18. Correspondence between vertical wavenumbers $k_{z}$ and perpendicular baselines $B_{\perp}$ as a function of the incident angle and the orbital altitude. 

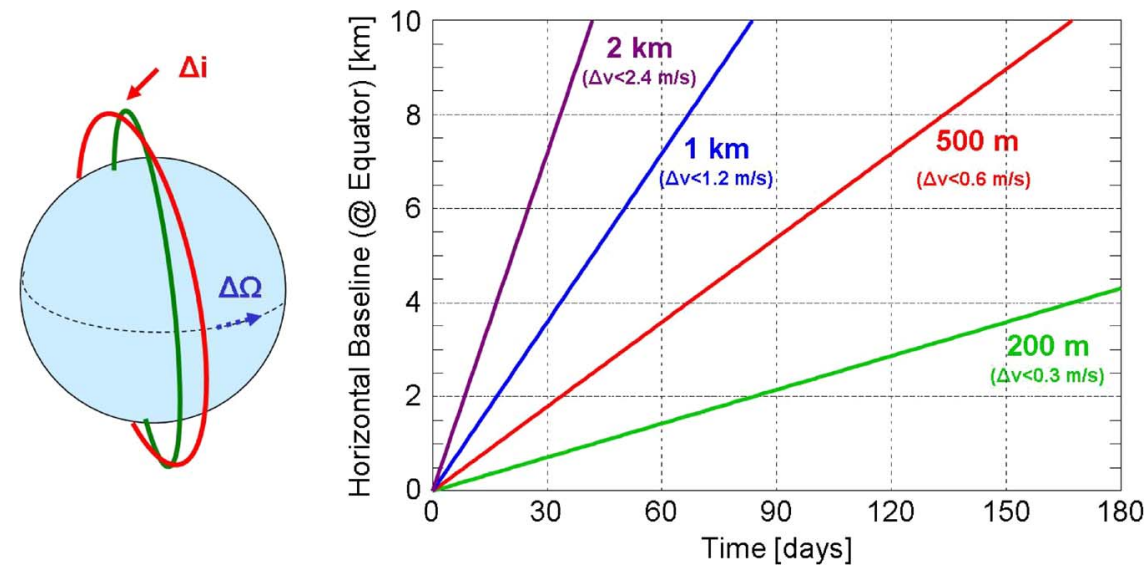

Fig. 19. A systematic variation of the equatorial cross-track baselines can be achieved by using orbits with slightly different inclinations $(\Delta \mathrm{i})$. The inclination offset causes a relative drift of the ascending nodes $(\Delta \Omega)$. The values for $\Delta \mathrm{v}$ represent the required velocity change to adjust the given inclination offsets.

The current Tandem-L design foresees an eight-day repeat orbit with an altitude of $760 \mathrm{~km}$, but there is still the option to lengthen the repeat cycle in favor of the ability to cover each area with at least two different incident angles. In any case, a minimum swath width of $350 \mathrm{~km}$ will be required to provide full spatial coverage at the equator without loosing satellite passes for high precision repeatpass interferometry.

The imaging of wide swaths with reasonable range and azimuth resolutions requires an extremely capable SAR instrument with a large antenna aperture. Two basic designs have been investigated for Tandem-L. The first design is based on a planar direct radiating array, while the

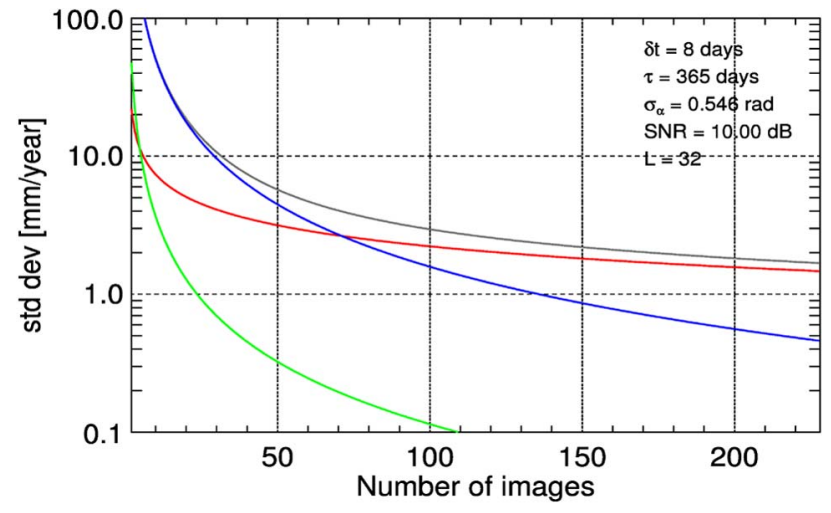

Fig. 20. Performance prediction example for the deformation mode. The colored curves show the individual error contributions from SNR decorrelation (green), atmosphere (blue), and temporal decorrelation (red). The overall error is shown in gray. The model in [72] has been used assuming a repeat orbit of $\delta t=8$, an exponential coherence decay with $\tau=365$ days, an atmospheric phase error standard deviation of $0.546 \mathrm{rad}(10 \mathrm{~mm}$ at L-band), an SNR of $10 \mathrm{~dB}$, and $L=32$ independent looks. second design employs a deployable reflector antenna. A deployable reflector has the great advantage to provide a large aperture at low weight and cost, but it may also require a more demanding orbit and attitude steering.

Unfurlable reflectors are now a mature technology with extensive flight heritage in space telecommunications, and lightweight mesh reflectors with diameters of $20 \mathrm{~m}$ and more will be deployed in space in the near future. The mesh surface accuracies can meet requirements beyond Ka-band and are hence more than sufficient for an L-band radar mission. The combination of a large commercial reflector with conventional transmit/receive modules for L-band SAR imaging has first been suggested by NASA/JPL in the context of the DESDynI mission [71]. The original design employed either conventional wide-swath ScanSAR or narrow-swath fully polarimetric stripmap modes for the different target areas. In extension to this concept, a significantly more powerful SAR instrument arises if the large reflector is combined with a digital feed array as illustrated in Fig. 21 (see [73]-[75]).

In this advanced concept, the simultaneous activation of all feed elements generates a broad transmit beam without spill-over as desired for wide swath illumination. On the other hand, radar echoes arriving as plane waves from a given direction activate typically only one or a small number of feed elements if the feed array is located close to the focal plane. This systematic correspondence between beam direction and activated feed array element(s) is well suited to significantly enhance the imaging performance of Tandem-L without an undue increase of the implementation complexity and the costs of the radar instrument. For example, a significant improvement in radar sensitivity and range ambiguity suppression is achieved via a dynamic routing of the individual feed signals. The selective routing corresponds to a real-time digital beamforming where a narrow antenna beam with 


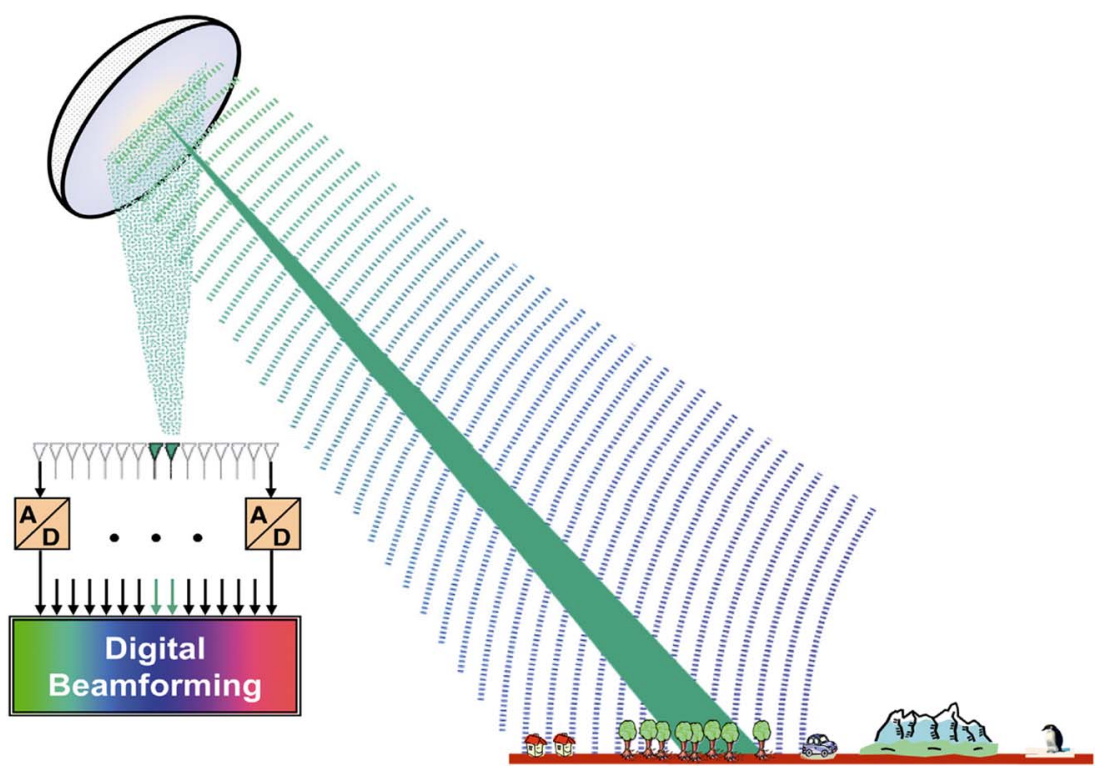

Fig. 21. Digital beamforming with large reflector antennas.
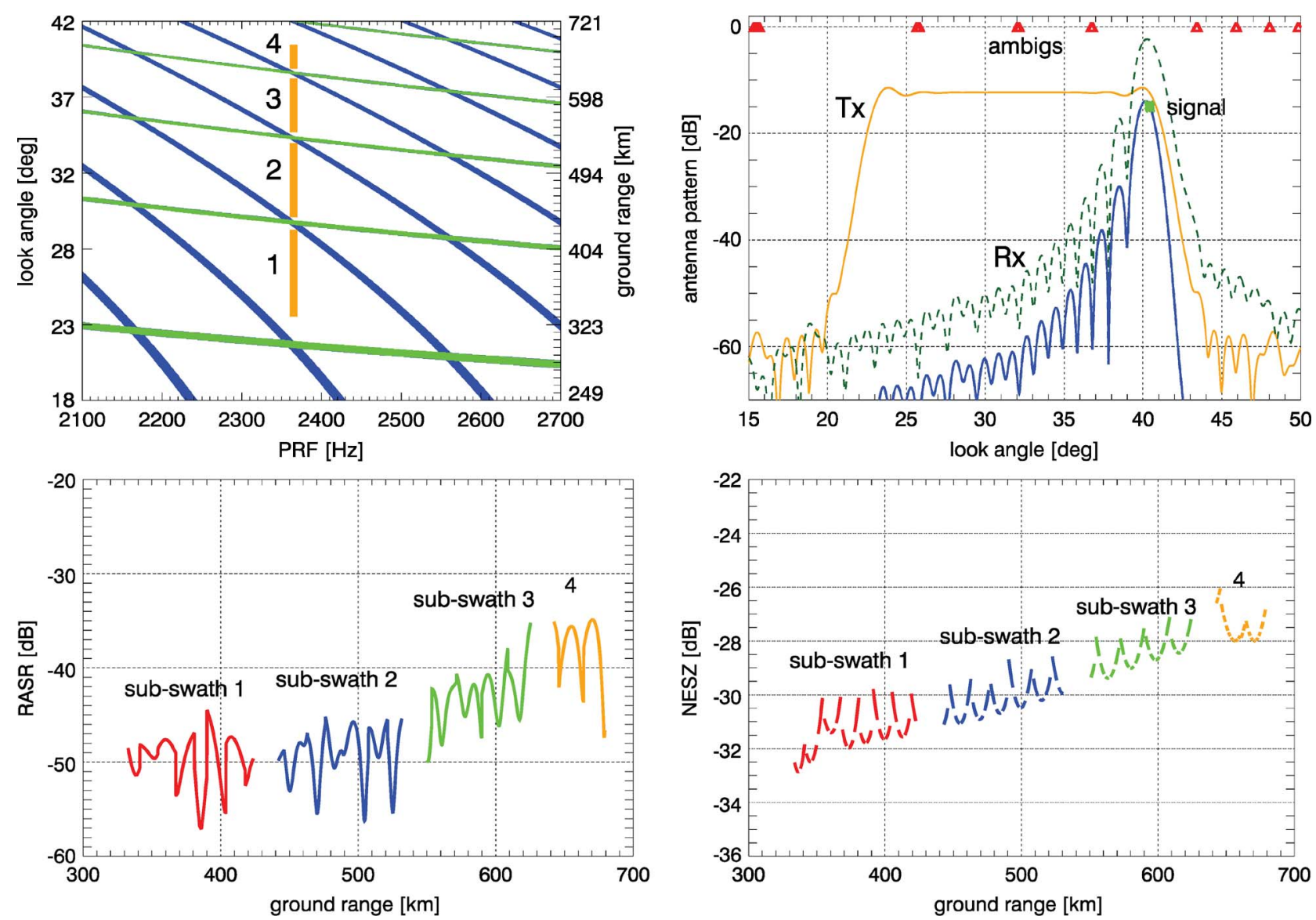

Fig. 22. Performance prediction for a $350 \mathrm{~km}$ quad-pol stripmap acquisition with four beams. Shown are (upper left) the timing diagram; (upper right) the transmit, receive, and combined antenna patterns; (lower left) the range ambiguities; and (lower right) the NESZ for the instrument parameters of Table 3. NESZ is the noise equivalent sigma zero and RASR is the range ambiguity to signal ratio. The blue areas in the upper left plot are the blind ranges, and the green areas represent nadir echoes. 
Table 3 Summary of System Parameters Used in Fig. 22

\begin{tabular}{|lclc|}
\hline Parameter & Value & Parameter & Value \\
\hline Orbit Height & $760 \mathrm{~km}$ & Reflector Size & $15 \mathrm{~m}$ (diameter) \\
Repeat Cycle & $8 \mathrm{days}$ & Focal Length & $10 \mathrm{~m}$ \\
Incident Angle & $26.3^{\circ}-46.6^{\circ}$ & Feed Location & centre \\
Look Angle & $23.3^{\circ}-40.5^{\circ}$ & Feed Elements & 24 \\
Swath Width & $349 \mathrm{~km}$ & Feed Length & $3.43 \mathrm{~m}$ \\
Ground Range & $331-680 \mathrm{~km}$ & Tilt Angle & $31.9^{\circ}$ \\
Tx Power (avg.) & $96 \mathrm{~W}$ & System Loss & $1 \mathrm{~dB}$ \\
Duty Cycle & $4 \%$ & Rx Noise Temp. & $420 \mathrm{~K}$ \\
Bandwidth & $85 \mathrm{MHz}$ & PRF & $2365 \mathrm{~Hz}$ \\
Polarization & Quad (linear) & Az. Resolution & $10 \mathrm{~m}$ \\
\hline
\end{tabular}

high receiver gain is steered in synchrony with the systematic variation of the swath echoes' direction of arrival. The real-time beamsteering makes full use of the available antenna aperture for high-gain signal reception without losing the opportunity for wide swath coverage. The increased performance relaxes the thermal, power, and energy demands and/or allows for longer operation times as desired for a systematic Earth monitoring mission.

The digital beamforming architecture of Tandem-L can, moreover, improve the spatial coverage without reducing the geometric resolution. High-resolution acquisitions are, e.g., desired for systematic deformation measurements in urban areas, landslides, and the immediate neighborhood of faults, for ice flow velocity measurements and for 3-D structure measurements via polarimetric SAR interferometry, where a higher geometric resolution allows for an increased number of looks to improve the retrieval of vegetation parameters. The classical solution to wide-swath SAR imaging is ScanSAR, where the coverage is improved at the cost of an impaired azimuth resolution. Digital beamforming allows for new acquisition modes that avoid the resolution compromise of the ScanSAR technique. One example is the simultaneous imaging of multiple swaths [73]. For a reflector antenna, multiple beams can easily be formed by recording simultaneously displaced subsets of activated feed element signals. The simultaneous recording of multiple swaths allows for an improved coverage without deteriorating the azimuth resolution (as in the ScanSAR mode). The different swaths are separated by "blind ranges," as the radar cannot receive radar echoes while transmitting. Due to the high receiver gain, the transmit pulses can be made very short and the gaps become rather small. Fig. 22 shows a performance example for the imaging of a $350 \mathrm{~km}$ wide swath in full polarization using a four-beam stripmap mode.

The blind ranges can be filled in by using different PRFs for each satellite pass. This shifts the data gaps to different range positions. Another opportunity to avoid blind ranges is a systematic variation of the PRF during the data take [73]. Two PRFs are sufficient to provide full wide-swath coverage in a multibeam ScanSAR mode with only two bursts, while a continuous sawtooth-like PRF variation generates for each range position even longer bursts that are interrupted by short interburst gaps, as illustrated in Fig. 23. The long bursts improve the azimuth resolution and/or provide more independent looks for interferometric applications. Very short transmit (Tx)

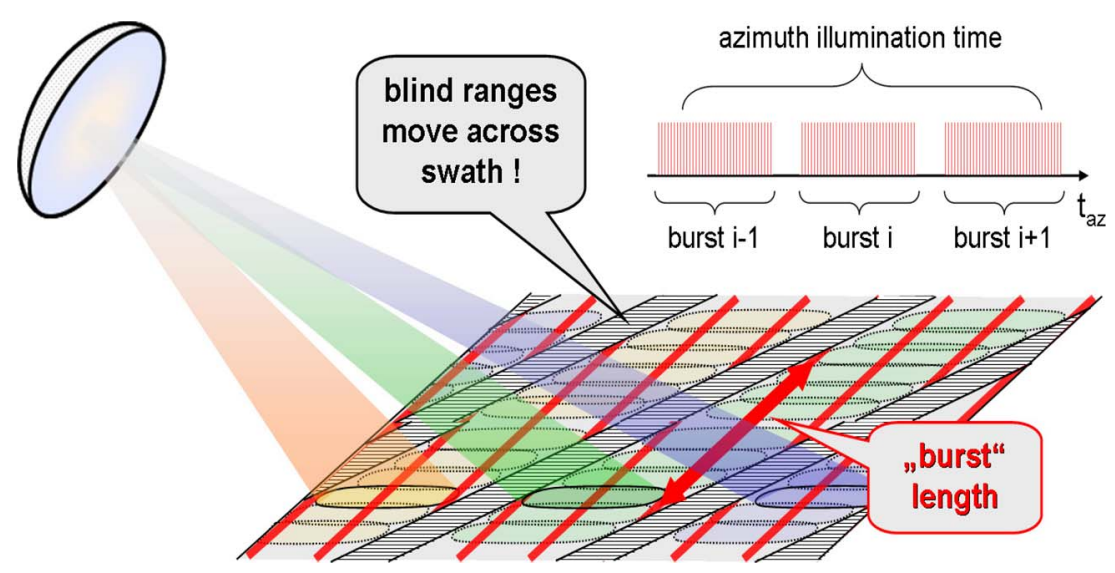

Fig. 23. Multiple swath imaging with variable PRF. Nadir echoes are sufficiently suppressed by combining the Tx antenna pattern with the narrow receiver beams obtained from the real-time digital beamforming. 


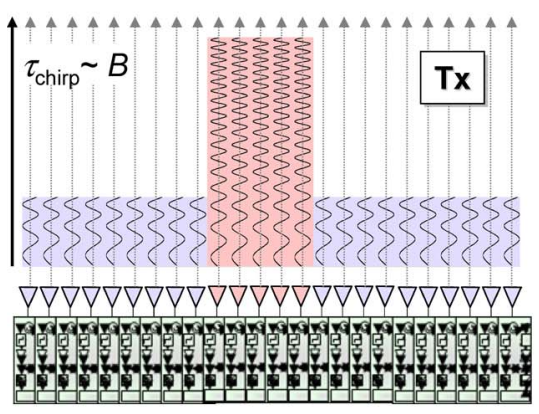

(a)

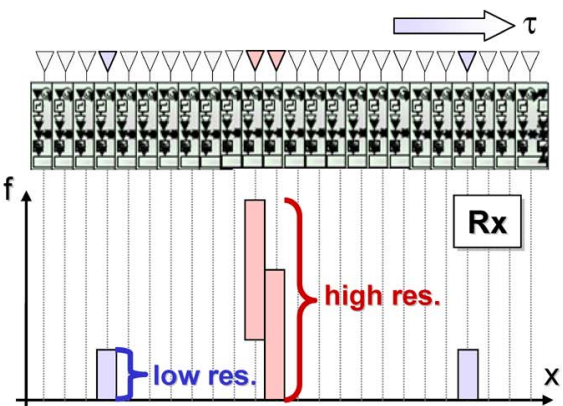

(b)

Fig. 24. Feed activation patterns for a hybrid SAR mode with variable range resolution. (a) Transmission with space-variant chirp bandwidth $B$ and pulse duration $\tau_{\text {chirp. }}$ (b) Snapshot of the received signals in a space-frequency representation. The filled bars denote those areas where the short-term power spectral density exceeds a given threshold.

pulses may even allow for an interpolation in azimuth at the cost of a slightly increased integrated sidelobe ratio. This could provide full stripmap resolution for a $350-\mathrm{km}$ wide swath without any gaps [73].

Often, the user requirements ask for high-resolution data takes within a small area like in the immediate neighborhood of volcanoes, faults, cities or steep slopes, while at the same time continuous wide-swath coverage with a coarser resolution is needed to remove, e.g., largescale disturbances from atmospheric signal delays. The brute force approach to meet these requirements is a continuous acquisition of very wide swaths with high geometric resolution as outlined in the previous section. However, such a global-scale high-resolution wide-swath imaging is also associated with a huge data volume, thereby increasing the demands for internal data storage, downlink, ground processing and archiving. A promising solution to these challenges is the use of new hybrid SAR modes [76]. These modes can be tailored to provide a variable resolution within the imaged scene and are hence well suited to resolve user and application conflicts without an explosion of the data volume, thereby maximizing the information about the Earth system dynamics under the constraint of a limited downlink and storage capacity.

Fig. 24 shows as an example the feed activation pattern $^{4}$ for one possible implementation of a hybrid SAR mode. In this example, a subset of the feed elements transmits a linear frequency-modulated chirp signal of full bandwidth while the remaining feed elements transmit only a portion of the chirp with the same chirp rate. The shortened pulse durations for most of the feed elements reduce the average transmit power if compared to a full high-resolution wide-swath SAR system.

The recording of the scattered signals is shown in Fig. 24 on the right. Only a small subset of the feed ele-

\footnotetext{
${ }^{4}$ Hybrid modes can also be implemented with a direct radiating array [76].
}

ments receives swath echoes at a given instant of time. From these feed elements, again only a small subset receives a full bandwidth signal while the residual activated feed elements receive a short narrow-band signal that can be sampled at a much lower frequency, thereby significantly reducing the overall data volume.

The hybrid mapping of wide swaths requires in general also a systematic variation of the PRF to avoid blind ranges. ${ }^{5}$ One opportunity is the combination of a local high-resolution stripmap acquisition with a wide-swath ScanSAR mode. Such a StripScan hybrid provides a nonhomogeneous resolution in azimuth and allows for a further reduction of the data volume. For this, the feed elements illuminating the wide swath are operated in bursts. This reduces both the average Tx power and the number of simultaneously activated feeds during signal reception. The hybrid of stripmap and ScanSAR makes the PRF selection more stringent, since one has to avoid gaps in both the stripmap and the ScanSAR subswaths. Suitable PRFs can be found since the high-resolution area covers only a portion of a full stripmap swath. The timing benefits moreover from the short Tx pulses and the active nadir echo suppression via the narrow receive $(\mathrm{Rx})$ beams. As an alternative, one may again consider a continuous variation of the PRF as outlined in the previous section (see Fig. 23).

An even more advanced hybrid SAR mode uses both Tandem-L satellites for a simultaneous scene illumination in different modes. Such a multistatic hybrid is well suited to resolve acquisition conflicts in areas that shall continuously be observed by both the deformation and the 3-D structure modes. One possible implementation divides the frequency spectrum among the different

${ }^{5}$ Some applications may tolerate such gaps. A possible example is the removal of the atmospheric phase screen for large-scale deformation measurements. Low-resolution SAR data acquisitions are desired during each satellite pass, but small gaps would not significantly impair the deformation and/or phase screen estimates due to their wide-ranging spatial correlations. 


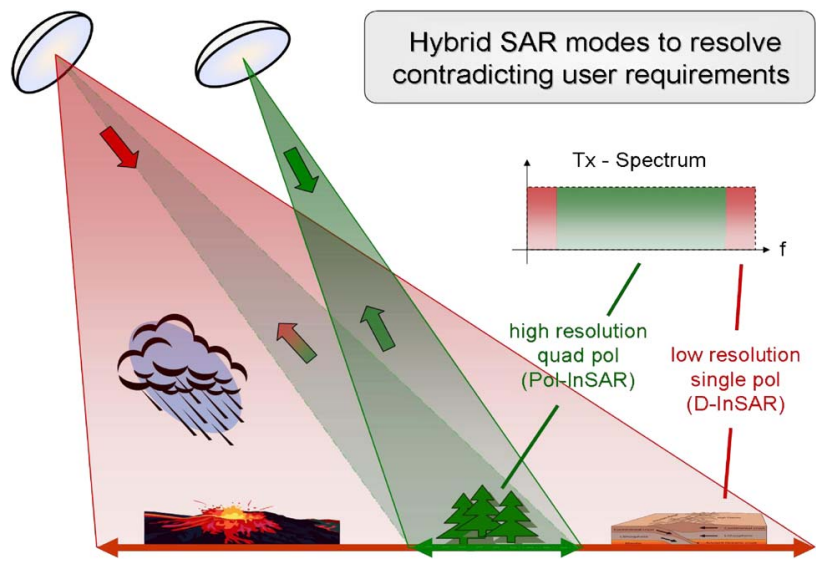

Fig. 25. Multistatic hybrid SAR mode for simultaneous 3-D structure and wide-swath deformation measurements. D-InSAR stands for differential SAR interferometry (i.e., deformation measurements) while PoI-InSAR stands for polarimetric SAR interferometry (i.e., 3-D structure measurements).

applications. As an example, one could use the central $60 \mathrm{MHz}$ of the available $85 \mathrm{MHz}$-band spectrum for 3-D structure measurements while leaving the remaining $25 \mathrm{MHz}$ for wide-swath deformation measurements as illustrated in Fig. 25. The satellite within the narrow repeat-pass orbital tube illuminates the wide swath using the $25 \mathrm{MHz}$ signal in a single polarization to acquire deformation data (e.g., at half PRF using one of the previously outlined imaging modes or by using full PRF and toggling between beams illuminating different swaths) while the other satellite with the variable baseline transmits in synchrony in alternating orthogonal polarizations. The second satellite records the $60 \mathrm{MHz}$ signals from the Pol-InSAR swath while the first records in addition the $25 \mathrm{MHz}$ signals from all feed elements. The simultaneous transmission with both satellites can moreover be used to synchronize both radar systems [53].

\section{FUTURE DEVELOPMENTS}

\section{A. Multibaseline DEM Generation}

The height sensitivity of a spaceborne SAR interferometer is significantly improved by increasing the distance between the satellites. However, a large baseline is also associated with a low height of ambiguity, which is defined as the vertical distance between two points that yield the same interferometric phase value. A lower height of ambiguity is hence well suited to increase the sensitivity, but

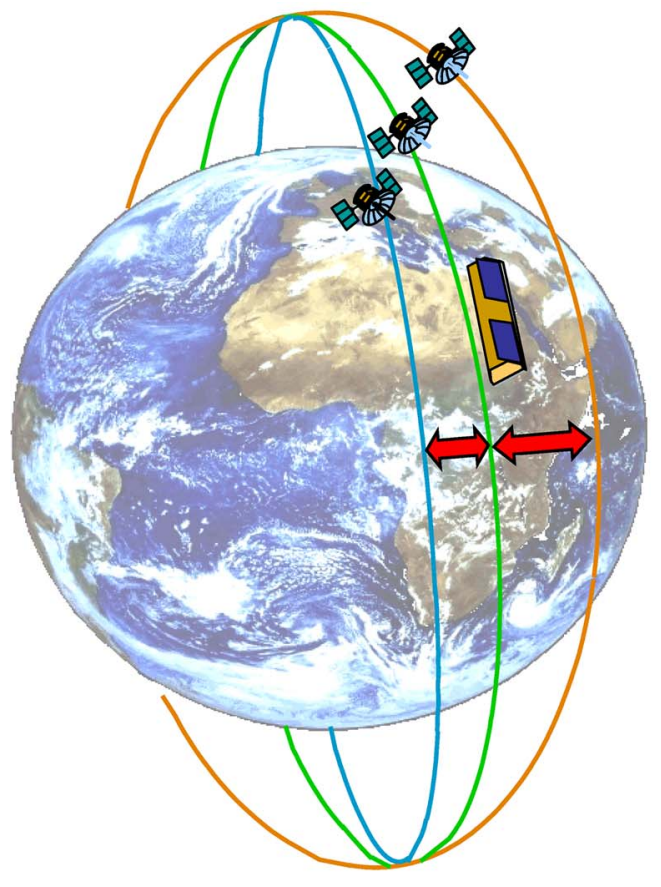

(a)

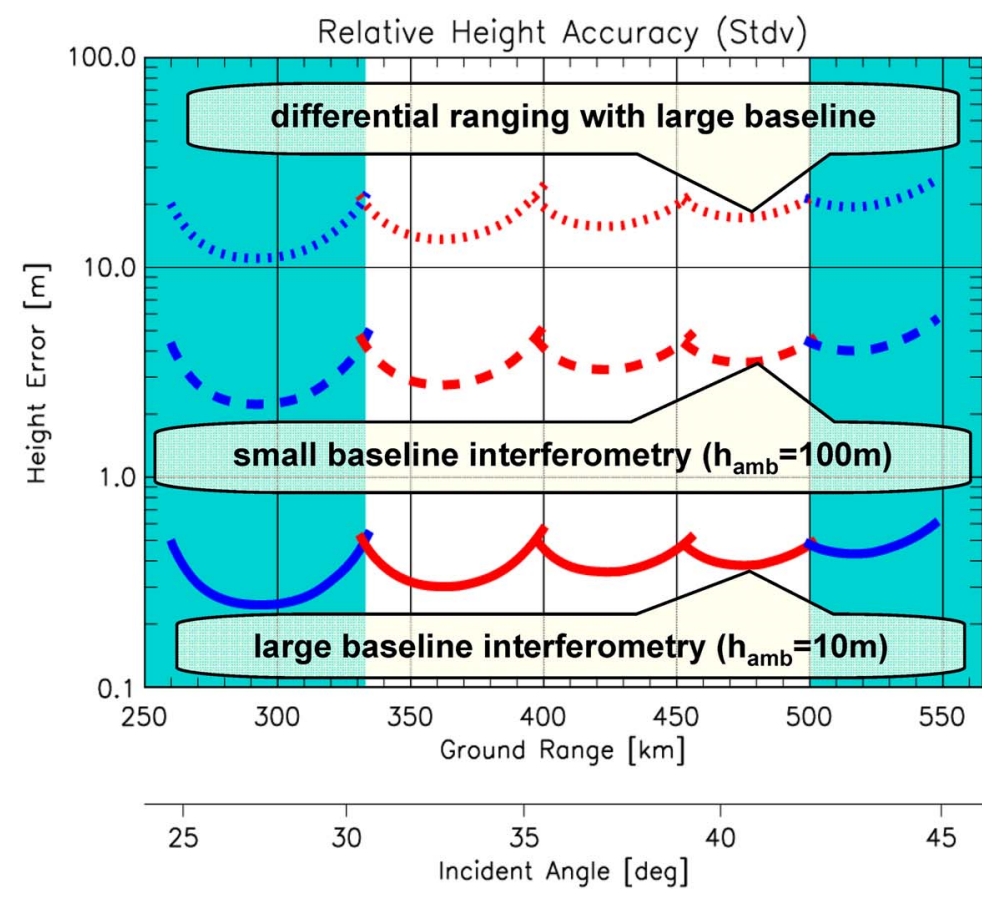

(b)

Fig. 26. (a) Semi-active L-band SAR formation with the receive-only satellites flying in a trinodal pendulum formation.

(b) Predicted DEM performance for multibaseline single-pass data acquisition. The interferometric height accuracy is shown for two baselines corresponding to a height of ambiguity of $100 \mathrm{~m}$ (dashed) and $10 \mathrm{~m}$ (solid). The dotted line is the predicted height accuracy for differential ranging. The height accuracy from differential ranging remains below the height of ambiguity of the small baseline interferometry, thus enabling efficient ambiguity suppression without the need for phase unwrapping. 


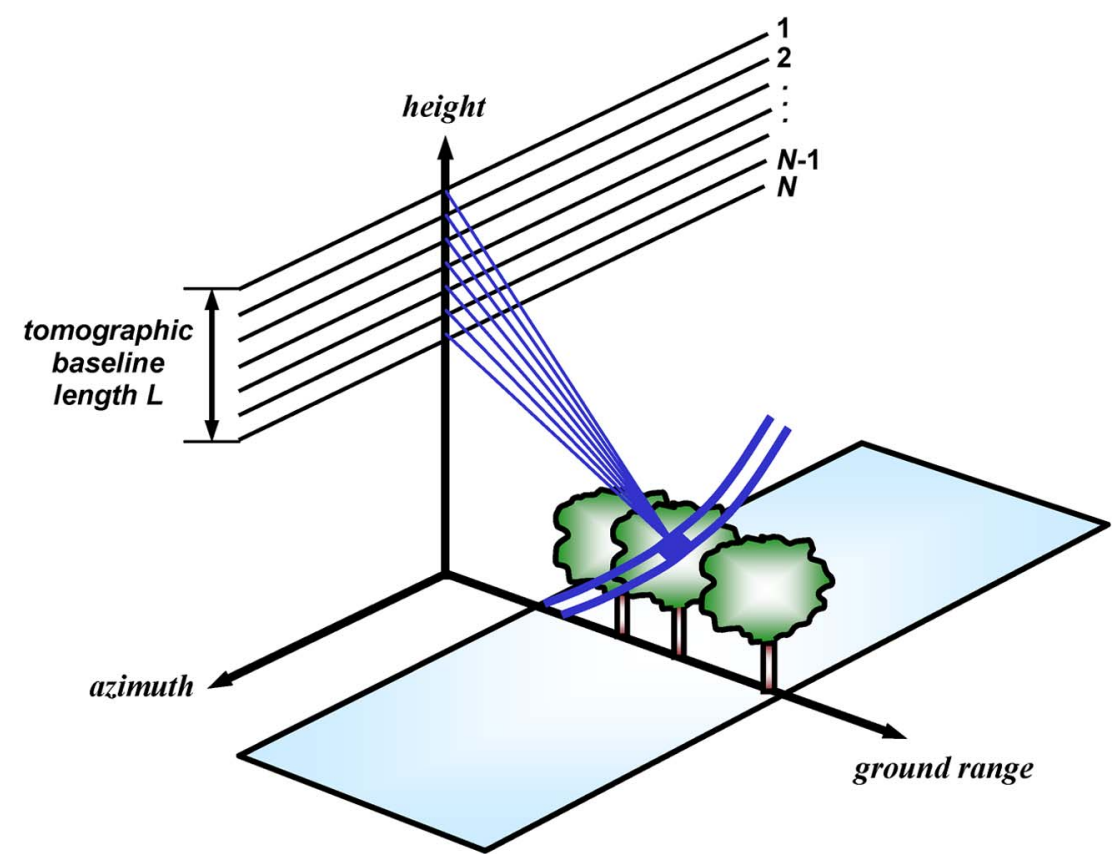

Fig. 27. Flight geometry for SAR tomography. A multistatic configuration consisting of several receive-only microsatellites flying in formation can be used in case of a spaceborne system realization.

it means also that it becomes more and more difficult to resolve phase ambiguities in the phase-to-height conversion process. To avoid such difficulties, TanDEM-X uses only a rather large height of ambiguity of 30 to $40 \mathrm{~m}$, which corresponds to less than $5 \%$ of the maximum possible baseline length [53]. Future satellite formations with more than two receivers allow for the simultaneous acquisition of multiple SAR interferograms in a single satellite pass as illustrated in Fig. 26(a). Their combination enables a reliable resolution of ambiguities and by this the costefficient acquisition of a global DEM with decimeter accuracy [77].

These multibaseline techniques can also be combined with differential ranging, which estimates the mutual range shift between corresponding pixels of two complex SAR images [78], [79]. The height accuracy from such an absolute phase estimation is usually not sufficient for the generation of high-resolution DEMs, but it can be used to resolve residual phase ambiguities in a multibaseline SAR interferometer [80]. This is illustrated in Fig. 26 for a semiactive L-band SAR formation with two interferometric baselines that are provided by three small receive-only satellites (see [77]).

The performance example shows that the height of ambiguity of the small baseline interferogram $\left(h_{\mathrm{amb}}=100 \mathrm{~m}\right)$ remains well above the height accuracy obtained by differential ranging with the large baseline. The combination of the two interferograms with differential ranging is hence sufficient to recover the height without phase unwrapping. By this, it becomes possible to push the DEM performance up to the limits of the critical baseline, which enables powerful SAR interferometers for the acquisition of high-resolution DEMs with a vertical accuracy below $1 \mathrm{~m}$. A suitable satellite formation for such a multibaseline SAR interferometer is the Trinodal Pendulum shown in Fig. 26(a), which acquires all interferometric data in a single pass using the same imaging geometry, thereby enabling an efficient fusion of the SAR image stack in radar slant range geometry. Multiple baseline interferometry has furthermore the potential to resolve phase ambiguities in areas with high vegetation and to solve problems from foreshortening and layover. Further opportunities arise from a joint evaluation of multibaseline coherence, which reflects important structural characteristics of both volume and surface scattering.

\section{B. SAR Tomography}

A constellation of multiple radar satellites recording the scattered signals from a common illuminated footprint can be regarded as a large aperture system with sparsely distributed subaperture elements. The combination of multiple receiver signals can hence be treated in the framework of array processing. A prominent example is SAR tomography, which combines the signals from several receivers to form a sparse aperture perpendicular to the flight direction (e.g., in the elevation plane; see Fig. 27) [81]-[85]. This enables a real 3-D imaging of semitransparent volume scatterers like e.g., vegetation, dry soil, sand, or ice. SAR tomography has furthermore the 
potential to resolve SAR image distortions due to layover and foreshortening [83], [85]. Besides some laboratory experiments, SAR tomography has up to now only been demonstrated by using multiple passes either in an airborne [82] or a spaceborne configuration [84]. In these examples, major problems arise from temporal decorrelation and unevenly spaced passes, which both limit the achievable performance and require a sophisticated processing to avoid high sidelobes in the tomographic response. Pendulum-like satellite formations as shown in Fig. 26 are well suited to overcome such limitations by providing multiple baselines with a precisely adjustable baseline ratio in a single pass. Further advantages of singlepass multistatic data acquisitions are improved baseline knowledge, no distortions due to scatterer movements, the cancellation of atmospheric disturbances, and better predictability of the noise level within each channel, thereby improving the inversion performance significantly. The minimization of such disturbances becomes even more important, as advanced SAR tomography techniques try to incorporate more and more a priori information in the multibaseline inversion process to, e.g., increase the resolution beyond the Rayleigh limit given by the maximum baseline length (an extreme example is conventional DEM generation, which assumes exactly one horizontal layer within each resolution cell).

For generating a tomographic image, one has first to process the individual SAR images acquired in a multipass or single-pass geometry. The coregistration of the images must be performed with subpixel accuracy, and precise phase preservation is required including the accurate correction of possible motion errors. In a second step, the tomographic processing is performed by a coherent combination of the images in order to form a synthetic aperture in the elevation plane. The synthetic aperture consists of $N$ points and has a total extension of $L$. While the synthetic aperture length defines the tomographic resolution, the distance between the individual passes determines the unambiguous volume height to be imaged [82]. Typical numbers for $N$ range between six and 15. Due to the low number of points, a time-domain processing can be adopted for the tomographic processing. Alternatively, a spectral analysis approach can also be used if an interpolation to equalize the distance between the passes has been performed in advance.

A tomographic experiment has been performed in 1998 using fully polarimetric L-band data of the airborne E-SAR system of DLR [82]: 14 tracks were flown by the E-SAR system with a nominal spacing of $20 \mathrm{~m}$, which is required for an unambiguous tomographic imaging up to approximately $35 \mathrm{~m}$. The tomographic synthetic aperture was about $240 \mathrm{~m}$, leading to a height resolution of $3 \mathrm{~m}$. The temporal decorrelation between the images was very small, showing a coherence higher than 0.9 even over forested areas.

Investigations of a spruce forest area reveal the potential of SAR tomography, especially in combination with polarimetry. As shown in Fig. 28, the following contributions can easily be distinguished: 1) dihedral scattering with a phase center at a height of circa $5 \mathrm{~m}$ due to the ground and stem interaction (clearly seen in the $\mathrm{HH}-\mathrm{VV}$ channel of the Pauli decomposition) and 2) random volume scattering in the crowns (dominant in HV-polarization). The separation of the scattering centers in height between ground and canopy also gives a good indication of forest height (circa $20 \mathrm{~m}$ ) and height of crown above ground, and indicates no presence of understory vegetation for this forest type. Several other tomographic plots of deciduous and mixed forests have shown that the canopy can generally be assumed to be a random volume at L-band,
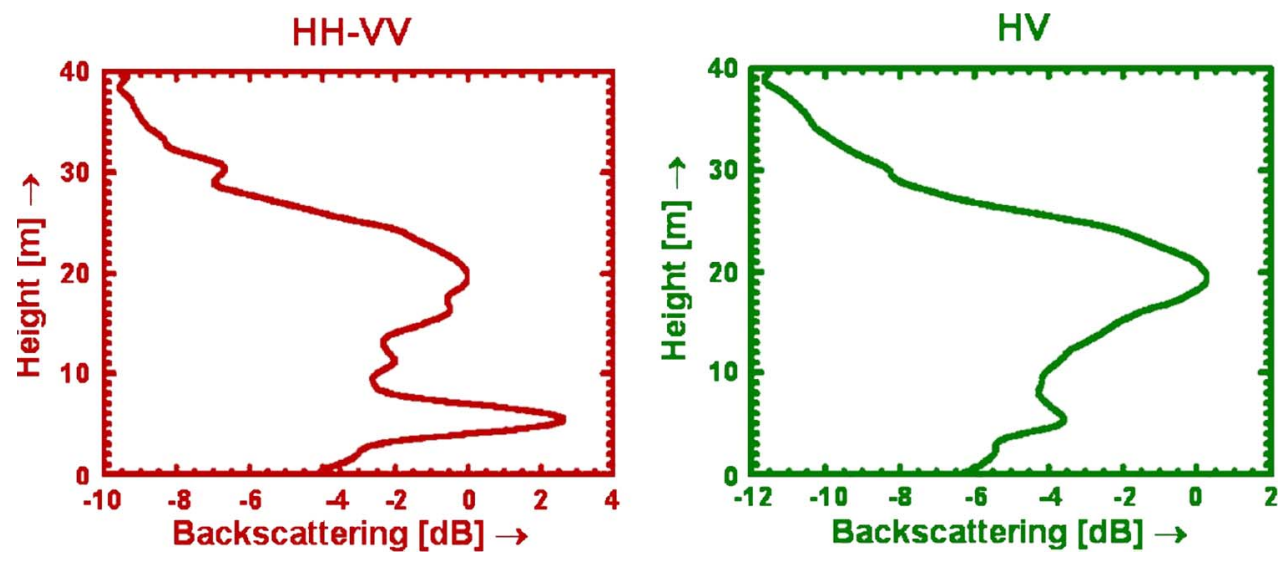

Fig. 28. Distribution of backscatter intensity versus height for a spruce forest in different polarizations (HH-VV and HV) reconstructed from 14 fully polarimetric L-band SAR images acquired with DLR's airborne E-SAR system. The plot on the left shows the strong reflection caused by the double bounce scattering due to the interaction between tree trunk and ground (observed in the HH-VV channel of the Pauli polarimetric representation). On the right, the dominant reflection of the canopy observed in the cross-polarization channel $(\mathrm{HV}+\mathrm{VH})$ is recognized. $\mathrm{H}$ and $\mathrm{V}$ stand for horizontal and vertical polarization, and the first and second letters represent the received and transmitted polarizations, respectively. 
confirming the model used for height retrieval with the polarimetric SAR interferometric technique.

Today's research work concentrates on the reduction of the number of acquisitions, for example, by means of spectral estimation techniques [86]. Further research is being performed toward the spaceborne implementation of tomography, for example, in connection with the interferometric Cartwheel or Trinodal Pendulum. With the selection of proper orbit configurations, three or four microsatellites in a repeat-pass scenario can acquire suitable tomographic data after two to three revisit cycles of the satellites. The effect of the temporal decorrelation in this acquisition scenario related to the selection of the optimal baselines is also a research topic.

Tomographic techniques can moreover be combined with applications from cross-track interferometry. One example is layover resolution in conjunction with multibaseline DEM generation. This enables data takes with steep incident angles, thereby increasing the SNR and avoiding DEM voids due to shadows. Steep incident angle imaging is also of high interest for urban environments and deep valleys. First steps in this direction have already been made in [85], but further work is required to apply such techniques to a real-world environment with, e.g., multipass effects in urban areas, uneven satellite orbit spacing, unknown number of layover layers, etc. Additional baselines for layover solution can also be acquired with multiple passes, but the spatiotemporal processing should then clearly differentiate between the errors from the highly coherent single pass acquisitions and the less coherent repeat pass acquisitions to optimize the performance.

\section{CONCLUSION}

This paper provides an overview of the advanced capabilities of single-pass SAR interferometry to map and monitor the Earth surface and its intricate dynamics. TanDEM-X will be the first single-pass multistatic SAR interferometer in space and has the primary objective to acquire a globally consistent and up-to-date DEM with unprecedented accuracy. Beyond its primary mission goal, TanDEM-X will also be an ideal testbed to demonstrate a multitude of new bistatic and multistatic interferometric SAR techniques and applications. As a further development, the mission proposal Tandem-L builds upon the know-how and experience gathered with TanDEM-X, especially in the areas of close formation flying, system synchronization, and systematic data-acquisition planning. In addition, highly innovative SAR imaging techniques have been developed to overcome the restrictions imposed by the limited mapping capabilities of traditional SAR systems. This supports a systematic global-scale data acquisition with very short repeat intervals and sufficient spatial resolution.

The advanced mapping capabilities of Tandem-L provide a unique database for new Earth observation applications. One example is the quasi-tomographic mapping of internal 3-D structure changes of semitransparent volume scatterers via the repeated acquisition of single-pass SAR interferograms [53]. This will provide important information about structural processes in vegetation, ice, permafrost soils, etc., and we expect a range of novel applications emerging from the advanced interferometric measurement capabilities. Tandem-L can be regarded as a first step towards a global monitoring system for the quasi-continuous observation of natural and anthropogenic processes that continuously restructure the Earth surface. Radar is the optimum sensor for continuous Earth system monitoring since it provides high-resolution images independent of weather conditions at day and night. Together with its unique ability to measure subtle changes with millimetric accuracy and its even more unique ability to obtain quasi-tomographic images from space, radar will likely become the most important sensor for a huge amount of remote sensing applications, most of which we are currently even not thinking about. It is our responsibility to develop the best tools and techniques to be able to deal with the upcoming challenges in a rapidly changing world and environment. The missions and concepts outlined in this paper are first steps in this direction.

\section{Acknowledgment}

The authors thank M. Eineder for collecting the science requirements for the Tandem- $\mathrm{L}$ deformation mode and providing the right illustration in Fig. 16, F. Kugler for his help in evaluating the forest science requirements, P. Prats and F. de Zan for conducting the deformation accuracy predictions in Fig. 20, S-K. Lee for his assistance in 3-D structure performance estimation, H. Fiedler and F. de Zan for their support in orbit and mission analysis, S. Huber and A. Patyuchenko for their help in the instrument performance investigations, A. Reigber for providing Fig. 28, and R. Scheiber for supplying Figs. 2 and 4. They thank the anonymous reviewers for their valuable comments and suggestions that helped to improve the manuscript. They also highly acknowledge the great effort and enthusiasm of both the DLR and the EADS Astrium teams to implement the ambitious TanDEM-X mission in space.

\section{REFERENCES}

[1] C. Elachi, Spaceborne Radar Remote Sensing: Applications and Techniques. New York: IEEE Press, 1988.

[2] J. C. Curlander and R. N. McDonough, Synthetic Aperture Radar: Systems and
Signal Processing. New York: Wiley, 1991.

[3] F. M. Henderson and A. J. Lewis, Eds., Manual of Remote Sensing: Principles and Applications of Imaging Radar. New York: Wiley, 1998.
[4] R. Gens and J. L. van Genderen, "SAR interferometry-Issues techniques, applications," Int. J. Remote Sens., vol. 17, pp. 1803-1835, 1996.

[5] S. N. Madsen and H. A. Zebker, "Imaging radar interferometry," in Manual of 
Radar Remote Sensing. New York: Wiley, 1998.

[6] D. Massonnet, "Radar interferometry and its application to changes in the earth's surface," Rev. Geophys., vol. 36, pp. 441-499, 1998.

[7] R. Bamler and P. Hartl, "Synthetic aperture radar interferometry," Inverse Prob., vol. 14, pp. 1-54, 1998.

[8] P. A. Rosen, S. Henseley, I. R. Joughin, F. K. Li, S. N. Madsen, E. Rodriguez, and R. Goldstein, "Synthetic aperture radar interferometry," Proc. IEEE, vol. 88, pp. 333-382, 2000.

[9] R. Hanssen, Radar Interferometry: Data Interpretation and Error Analysis. Dordrecht, The Netherlands: Kluwer Academic, 2001.

[10] L. C. Graham, "Synthetic interferometer radar for topographic mapping," Proc. IEEE, vol. 62, pp. 763-768, 1974

[11] H. A. Zebker and R. Goldstein, “Topographic mapping from interferometric synthetic aperture radar observations," J. Geophys. Res. vol. 91, pp. 4993-4999, 1986.

[12] R. M. Goldstein and H. A. Zebker, "Interferometric radar measurement of ocean surface currents," Nature, vol. 328 , pp. 707-709, 1987.

[13] R. M. Goldstein, T. P. Barnett, and H. A. Zebker, "Remote sensing of ocean currents," Science, vol. 246, pp. 1282-1285, 1989.

[14] A. L. Gray and P. J. Farris-Manning, "Repeat-pass interferometry with airborne synthetic aperture radar," IEEE Trans. Geosci. Remote Sens., vol. 31, pp. 180-191, 1993.

[15] R. E. Carande, "Estimating ocean coherence time using dual-baseline interferometric synthetic aperture radar," IEEE Trans. Geosci. Remote Sens., vol. 32, pp. 846-854, 1994.

[16] K. P. Papathanassiou and S. R. Cloude, "Single-baseline polarimetric SAR interferometry," IEEE Trans. Geosci. Remote Sens., vol. 39, pp. 2352-2363, 2001.

[17] A. K. Gabriel and R. M. Goldstein, "Crossed orbit interferometry: Theory and experimental results from SIR-B," Int. J. Remote Sens., vol. 9, pp. 857-872, 1988.

[18] R. M. Goldstein, H. A. Zebker, and C. L. Werner, "Satellite radar interferometry: Two-dimensional phase unwrapping," Radio Sci., vol. 23, pp. 713-720, 1988.

[19] A. Gabriel, R. Goldstein, and H. A. Zebker, "Mapping small elevation changes over large areas: Differential radar interferometry," J. Geophys. Res., vol. 94, pp. 9183-9191, 1989.

[20] F. K. Li and R. M. Goldstein, "Studies of multibaseline spaceborne interferometric synthetic aperture radars," IEEE Trans. Geosci. Remote Sens., vol. 28, pp. 88-96, 1990.

[21] D. Massonnet, M. Rossi, C. Carmona, F. Adragna, G. Peltzer, K. Feigl, and T. Rabaute, "The displacement field of the landers earthquake mapped by radar interferometry," Nature, vol. 364 pp. 138-142, 1993.

[22] H. A. Zebker, P. A. Rosen, R. M. Goldstein, A. Gabriel, and C. L. Werner, "On the derivation of coseismic displacement fields using differential radar interferometry: The Landers earthquake," J. Geophys. Res., vol. 99, pp. 19 617-19 634, 1994
[23] R. M. Goldstein, H. Engelhardt, B. Kamb, and R. M. Frolich, "Satellite radar interferometry for monitoring ice sheet motion: Application to an antarctic ice stream," Science, vol. 262, pp. 763-768, 1993.

[24] H. A. Zebker and J. Villasenor, "Decorrelation in interferometric radar echoes," IEEE Trans. Geosci. Remote Sens., vol. 30, pp. 950-959, 1992.

[25] J. Askne and J. O. Hagberg, "Potential of interferometric SAR for classification of land surfaces," in Proc. IEEE Geosci. Remote Sens. Symp., Tokyo, Japan, 1993.

[26] C. Prati, F. Rocca, and A. Monti Guarnieri, "SAR interferometry experiments with ERS-1," in Proc. 1st ERS-1 Symp., Cannes, France, 1992, pp. 211-218.

[27] J. O. Hagberg, L. M. H. Ulander, and J. Askne, "Repeat-pass SAR interferometry over forested terrain," IEEE Trans. Geosci. Remote Sens., vol. 33, pp. 331-340, 1995.

[28] U. Wegmuller and C. L. Werner, "SAR interferometric signatures of forest," IEEE Trans. Geosci. Remote Sens., vol. 33, pp. 1153-1163, 1995.

[29] U. Wegmuller and C. Werner, "Retrieval of vegetation parameters with SAR interferometry," IEEE Trans. Geosci. Remote Sens., vol. 35, pp. 18-24, 1997.

[30] D. Massonnet, P. Briole, and A. Arnaud, "Deflation of mount Etna monitored by spaceborne radar interferometry," Nature, vol. 375, pp. 567-570, 1995.

[31] P. Dammert, M. Lepparanta, and J. Askne, "SAR interferometry over Baltic sea ice," Int. J. Remote Sens., vol. 19, pp. 3019-3037, 1998.

[32] S. R. Cloude and K. P. Papathanassiou, "Polarimetric SAR interferometry," IEEE Trans. Geosci. Remote Sens., vol. 36, pp. 1551-1565, 1998.

[33] D. Massonet, T. Holzer, and H. Vadon, "Land subsidence caused by the East Mesa geothermal field, California, observed using SAR interferometry," Geophys. Res. Lett., vol. 24, pp. 901-904, 1997.

[34] A. Ferretti, C. Prati, and F. Rocca, "Nonlinear subsidence rate estimation using permanent scatterers in differential SAR interferometry," IEEE Trans. Geosci. Remote Sens., vol. 38 , pp. 2202-2212, 2000.

[35] H. Breit, M. Eineder, J. Holzner, H. Runge, and R. Bamler, "Traffic monitoring using SRTM along-track interferometry," in Proc. IEEE Geosci. Remote Sens. Symp. (IGARSS), Toulouse, France, 2003.

[36] H. A. Zebker, T. G. Farr, R. P. Salazar, and T. H. Dixon, "Mapping the world's topography using radar interferometry: The TOPSAT mission," Proc. IEEE, vol. 82, pp. 1774-1786, 1994.

[37] I. Hajnsek and A. Moreira, "TanDEM-X: Mission and science exploration," in Proc. Eur. Conf. Synthetic Aperture Radar (EUSAR), Dresden, Germany, 2006.

[38] R. N. Treuhaft, S. N. Madsen, M. Moghaddam, and J. J. van Zyl, "Vegetation characteristics and underlying topography from interferometric radar," Radio Sci., vol. 31, pp. 1449-1485, 1996

[39] R. N. Treuhaft and P. R. Siqueira, "The vertical structure of vegetated land surfaces from interferometric and polarimetric radar," Radio Sci., vol. 35, pp. 141-177, 2000.

[40] I. Hajnsek, F. Kugler,

S. Lee, and K. Papathanassiou,

"Tropical-forest-parameter estimation by means of Pol-InSAR: The INDREX-II campaign," IEEE Trans. Geosci. Remote Sens., vol. 47, pp. 481-493, 2009.

[41] J. Praks, F. Kugler, K. Papathanassiou, I. Hajnsek, and M. Hallikainen, "Tree height estimation for boreal forest by means of L- and X-band PolInSAR and HUTSCAT profiling scatterometer," IEEE Geosci. Remote Sens. Lett., vol. 4, pp. 466-470, 2007.

[42] T. Mette, K. Papathanassiou, and I. Hajnsek, "Estimating forest biomass from polarimetric interferometric SAR data in combination with forest allometry-Results from temperate spruce forest tests site Traunstein," in Proc. Retrieval Bio Geophys. Parameters SAR Data Land Applicat., Innsbruck, Austria, Nov. 16-19, 2004.

[43] F. Kugler, F. N. Koudogbo, K. Papathanassiou, and K. Gutjahr, "Frequency effects in Pol-InSAR forest height estimation," in Proc. Eur. Conf. Synthetic Aperture Radar (EUSAR'06), Dresden, Germany, May 16-18, 2006.

[44] F. Garestier, P. Dubois Fernandez, and K. Papathanassiou, "Pine forest height inversion using single-pass X-band PolInSAR data," IEEE Trans. Geosci. Remote Sens., vol. 46, pp. 59-68, 2008.

[45] F. R. Dickey and M. M. Santa, "Final report on anti-clutter techniques General Electric Co., Rep. R65EMH37, Mar. 1, 1953.

[46] C. E. Livingstone, I. Sikaneta, C. H. Gierull, S. Chiu, A. Beaudoin, J. Campbell, J. Beaudoin, S. Gong, and T. A. Knight, "An airborne synthetic aperture radar (SAR) experiment to support RADARSAT-2 ground moving target inidication (GMTI)," Can. J. Remote Sens., vol. 28, pp. 794-813, 2002.

[47] R. Romeiser, H. Breit, M. Eineder, H. Runge, P. Flament, J. de Karin, and J. Vogelzang, "Current measurements by SAR along-track interferometry from a space shuttle," IEEE Trans. Geosci. Remote Sens., vol. 43, pp. 2315-2324, 2005.

[48] M. Werner, "Shuttle Radar Topography Mission (SRTM) mission overview," Frequenz J. Telecommun., vol. 55, pp. 75-79, 2001.

[49] B. Rabus, M. Eineder, A. Roth, and R. Bamler, "The shuttle radar topography mission-A new class of digital elevation models acquired by spaceborne radar," Photogramm. Rem. Sens., vol. 57, pp. 241-262, 2003.

[50] T. G. Farr, P. Rosen et al., "The shuttle radar topography mission," Rev. Geophys., vol. 45, 2007, RG 2004.

[51] A. Moccia and S. Vetrella, "A tethered interferometric synthetic aperture radar (SAR) for a topographic mission," IEEE Trans. Geosci. Remote Sens. vol. 30, pp. 103-109, 1992.

[52] D. Massonnet, "Capabilities and limitations of the interferometric cartwheel," IEEE Trans. Geosci. Remote Sens., vol. 39, pp. 506-520, 2001.

[53] G. Krieger, A. Moreira, H. Fiedler, I. Hajnsek, M. Werner, M. Younis, and M. Zink, "TanDEM-X: A satellite formation for high resolution SAR interferometry," IEEE Trans. Geosci. Remote Sens., vol. 45 pp. 3317-3341, 2007.

[54] E. Rodriguez and J. M. Martin, "Theory and design of interferometric synthetic aperture radars," Proc. Inst. Elect. Eng. F, Radar Signal Process., vol. 139, pp. 147-159, 1992. 
[55] R. Werninghaus and S. Buckreuss, "The TerraSAR-X mission and system design," IEEE Trans. Geosci. Remote Sens., vol. 48, pp. 606-614, 2010

[56] M. Stangl, R. Werninghaus, B. Schweizer, C. Fischer, M. Brandfass, J. Mittermayer, and H. Breit, "TerraSAR-X technologies and first results," Proc. Inst. Elect. Eng. Radar, Sonar Navig., vol. 153, pp. 86-95, 2006.

[57] F. Gatelli, A. M. Guamieri, F. Parizzi, P. Pasquali, C. Prati, and F. Rocca, "The wavenumber shift in SAR interferometry," IEEE Trans. Geosci. Remote Sens., vol. 32, pp. 855-865, 1994.

[58] S. R. Cloude and K. P. Papathanassiou, "Three-stage inversion process for polarimetric SAR interferometry," Proc. Inst. Elect. Eng. F, Radar Sonar Navig., vol. 150, no. 3, pp. 125-134, 2003.

[59] S. R. Cloude, "Polarization coherence yomography," Radio Sci, vol. 41, p. RS 4017, Sep. 2006.

[60] S. R. Cloude, "Dual baseline coherence tomography," IEEE Geosci. Remote Sens. Lett., vol. 4, pp. 127-131, Jan. 2007.

[61] G. Krieger and M. Younis, "Impact of oscillator noise in bistatic and multistatic SAR," IEEE Geosci. Remote Sens. Lett., vol. 3, pp. 424-428, 2006.

[62] M. Younis, R. Metzig, and G. Krieger, "Performance prediction of a phase synchronization link for bistatic SAR," IEEE Geosci. Remote Sens. Lett., vol. 3, pp. 429-433, 2006

[63] J. Mittermayer and H. Runge, "Conceptual studies for exploiting the TerraSAR-X dual receive antenna," in Proc. IEEE Geosci. Remote Sens. Symp., Toulouse, France, 2003.

[64] G. Krieger, K. Papathanassiou, and S. Cloude, "Spaceborne polarimetric SAR interferometry: Performance analysis and mission concepts," EURASIP J. Appl. Signal Process., vol. 20, pp. 3272-3292, 2005.

[65] G. Krieger and A. Moreira, "Spaceborne Bi- and multistatic SAR: Potential and challenges," Proc. Inst. Elect. Eng. Radar, Sonar Navig., vol. 153, pp. 184-198, 2006.

[66] P. Dubois-Fernandez, H. Cantalloube, B. Vaizan, G. Krieger, R. Horn, M. Wendler, and V. Giroux, "ONERA-DLR bistatic SAR campaign: Planning, data acquisition, and first analysis of bistatic scattering behavior of natural and urban targets," Proc. Inst. Elect. Eng. Radar, Sonar Navig., vol. 153, pp. 214-223, 2006

[67] P. Dubois-Fernandez, H. Cantalloube, B. Vaizan, G. Krieger, and A. Moreira, "Airborne bistatic synthetic aperture radar," in Bistatic Radar: Emerging Technology, M. Cherniakov, Ed. New York: Wiley, 2008, pp. 159-213.

[68] A. Moccia, N. Chiacchio, and A. Capone, "Spaceborne bistatic synthetic aperture radar for remote sensing applications," Int. J. Remote Sens., vol. 21, pp. 3395-3414, 2000.

[69] G. Krieger, N. Gebert, and A. Moreira, "Unambiguous SAR signal reconstruction from nonuniform displaced phase center sampling," IEEE Geosci. Remote Sens. Lett., vol. 1, pp. 260-264, 2004.

[70] A. Moreira, I. Hajnsek, G. Krieger, K. Papathanassiou, M. Eineder, F. De Zan, M. Younis, and M. Werner, "Tandem-L: Monitoring the earth's dynamics with InSAR and Pol-InSAR," in Proc. PolinSAR 2009, Frascati, Italy, Jan. 2009.

[71] A. Freeman, A. Donnellan, P. Rosen, D. Evans, J. Graf, A. Loverro, R. Treuhaft, R. Oberto, W. Johnson, M. Simard, T. Farr, E. Rignot, R. Kwok, and X. Pi, "Deformation, Ecosystem Structure, and Dynamics of Ice (DESDynI)," in Proc. EUSAR 2008, Friedrichshafen, Germany, May 2008.

[72] A. Monti Guarnieri and S. Tebaldini, "Hybrid Cramér-Rao bounds for crusta displacement field estimators in SAR interferometry," IEEE Signal Process. Lett. vol. 14, pp. 1012-1015, 2007.

[73] G. Krieger, N. Gebert, M. Younis, and A. Moreira, "Advanced synthetic aperture radar based on digital beamforming and waveform diversity," in Proc. IEEE Radar Conf., Rome, Italy, May 2008, pp. 767-772.

[74] A. Freeman, G. Krieger, P. Rosen, M. Younis, W. T. K. Johnson, S. Huber, R. Jordan, and A. Moreira, "SweepSAR: Beam-forming on receive using a reflector-phased array feed combination for spaceborne SAR," in Proc. IEEE Radar Conf., Pasadena, CA, May 2009.

[75] M. Younis, S. Huber, A. Patyuchenko, F. Bordoni, and G. Krieger, "Performance comparison of reflector- and planar-antenna based digital beam-forming SAR," Int. J.
Antennas Propag. (Special Issue on Active Antennas for Space Applications), 2009.

[76] G. Krieger, N. Gebert, and A. Moreira, "Multidimensional waveform encoding: A new digital beamforming technique for synthetic aperture radar remote sensing," IEEE Trans. Geosci. Remote Sens., vol. 46, pp. 31-46, Jan. 2008.

[77] G. Krieger and A. Moreira, "Spaceborne interferometric and multistatic SAR systems," in Bistatic Radar: Emerging Technology, M. Cherniakov, Ed. New York: Wiley, 2008, pp. 95-158.

[78] S. N. Madsen and H. A. Zebker, "Automated absolute phase retrieval in across-track interferometry," in Proc. IEEE Geosci. Remote Sens. Symp., Houston, TX, 1992.

[79] R. Bamler and M. Eineder, "Accuracy of differential shift estimation by correlation and split-bandwidth interferometry for wideband and delta-k SAR systems," IEEE Geosci. Remote Sens. Lett., vol. 2, pp. 151-155, 2005

[80] G. Krieger and A. Moreira, "Multistatic SAR satellite formations: Potentials and challenges," in Proc. IEEE Geosci. Remote Sens. Symp., Seoul, Korea, 2005.

[81] J. Homer, I. D. Longstaff, and G. Callaghan, "High resolution 3-D SAR via multi-baseline interferometry," in Proc. IEEE Geosci. Remote Sens. Symp., Lincoln, NE, 1996.

[82] A. Reigber and A. Moreira, "First demonstration of airborne SAR tomography using multibaseline L-band data," IEEE Trans. Geosci. Remote Sens., vol. 38, pp. 2142-2152, 2000

[83] F. Lombardini, M. Montanari, and F. Gini, "Reflectivity estimation for multibaseline interferometric radar imaging of layover extended sources," IEEE Trans. Signal Process., vol. 51, pp. 1508-1519, 2003.

[84] G. Fornaro, F. Lombardini, and F. Serafino, "Three-dimensional multipass SAR focusing: Experiments with long-term spaceborne data," IEEE Trans. Geosci. Remote Sens., vol. 43, pp. 702-714, 2005.

[85] F. Gini, F. Lombardini, and M. Montanari, "Layover solution in multibaseline SAR interferometry," IEEE Trans. Aerosp. Electron. Syst., vol. 38, pp. 1344-1356, 2002.

[86] M. Nannini, R. Scheiber, and A. Moreira, "Estimation of the minimum number of tracks for SAR tomography," IEEE Trans. Geosci. Remote Sens., vol. 47, pp. 531-543, 2009

\section{ABOUT THE AUTHORS}

Gerhard Krieger (Senior Member, IEEE) received the Dipl.-Ing. (M.S.) and Dr.-Ing. (Ph.D.) degrees (with honors) in electrical and communication engineering from the Technical University of Munich, Germany, in 1992 and 1999, respectively.

From 1992 to 1999, he was with LudwigMaximilians University, Munich, where he conducted multidisciplinary research on neuronal modeling and nonlinear information processing in biological and technical vision systems. In 1999, he joined the Microwaves and Radar Institute, German Aerospace Center (DLR), Oberpfaffenhofen, Germany, where he developed signal- and image-processing algorithms for a novel forward-looking radar system employing digital beamforming on receive. From 2001 to 2007, he led the New SAR Missions Group, which pioneered the development of advanced bistatic and multistatic radar systems as exemplified by the forthcoming TanDEM-X mission as well as innovative multichannel SAR techniques and algorithms for high-resolution wide-swath SAR imaging. Since 2008, he has been Head of the new Radar Concepts Department of the Microwaves and Radar Institute, DLR, Oberpfaffenhofen, Germany. He is the author of 30 peer-reviewed journal papers, four invited book chapters, more than 100 conference papers, and four patents. His current research interests focus on the development of multichannel radar techniques and algorithms for innovative MIMO SAR systems, the demonstration of novel interferometric and tomographic Earth observation applications, and the conceptual design of advanced bi- and multistatic radar missions.

Dr. Krieger has received several national and international awards, including the IEEE TRANSACtIons Prize Paper Award from the Geoscience and Remote Sensing Society and the Otto Lilienthal Sabbatical from the German Aerospace Center, DLR. 
Irena Hajnsek (Senior Member, IEEE) received the Dipl. degree (honors) from the Free University of Berlin, Germany, in 1996 and the Dr. degree (honors) from the Friedrich Schiller University, Jena, Germany, in 2001.

She is a Professor of Earth Observation at the ETH Zürich Institute of Earth Observation and Head of the Polarimetric SAR Interferometry research group at the German Aerospace Center Microwaves and Radar Institute. Her main re-

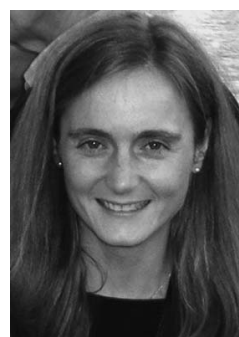
search interests are in electromagnetic propagation and scattering theory, radar polarimetry, SAR and interferometric SAR data-processing techniques, and environmental parameter modelling and estimation. From 1996 to 1999 , she was with the Microwaves and Radar Institute (DLR-HF), German Aerospace Center (DLR), Oberpfaffenhofen, Germany. From 1999 to 2000, she was with the Institut d'Electronique et de Télécommunications de Rennes, University of Rennes, France, and with Applied Electromagnetics, St. Andrews, Scotland, U.K., in the framework of the EC-TMR Radar Polarimetry Network. In 2005, she was a Guest Scientist with the University of Adelaide, South Australia. Since the beginning of the TanDEM-X project, she has been coordinating the TanDEM-X science team.

\section{Konstantinos Panagiotis Papathanassiou} (Senior Member, IEEE) received the Dipl.Ing and Dr. degree (both with honors) from the Technical University of Graz, Austria, in 1994 and 1999, respectively.

From 1992 to 1994, he was with the Institute for Digital Image Processing, Joanneum Research, Austria. Between 1995 and 1999, he was with the Microwaves and Radar Institute (HR), German Aerospace Center (DLR), Oberpfaffenhofen,

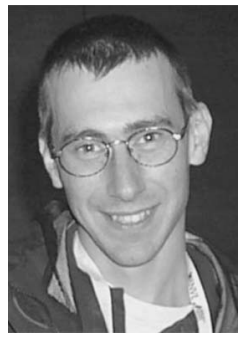
Germany. From 1999 to 2000, he was an EU Postdoctoral Fellow with Applied Electromagnetics (AEL), St. Andrews, Scotland, U.K. Since October 2000, he has been with HR, DLR, where he currently is a Senior Scientist leading the SAR System research group. His main research interests are in polarimetric and interferometric processing and calibration techniques, polarimetric SAR interferometry, and the quantitative parameter estimation from SAR data, as well as in SAR mission design and SAR mission performance analysis. He has more than 100 publications in international journals, conferences, and workshops.

Dr. Papathanassiou received the IEEE GRSS IGARSS Symposium Prize Paper Award in 1998, the Best Paper Award from the European SAR Conference (EUSAR) in 2002, and the DLR science award in 2002.

Marwan Younis (Senior Member, IEEE) was born in Las Cruces, NM, in 1970. He received the B.Sc. degree from the University of Baghdad, Iraq, in 1992 and the Dipl.-Ing. (M.Sc.) and Dr.-Ing. (Ph.D.) degrees from the Universität Karlsruhe, Germany, in 1997 and 2004, respectively, all in electrical engineering.

From 1998 to 2004, he was a Research Scientist with the Institut für Höchstfrequenztechnik und Elektronik, Universität Karlsruhe. Since
2005, he has been with the Microwaves and Radar Institute, German Aerospace Center (DLR), Oberpfaffenhofen, Germany. He is the author and coauthor of more than 70 conference papers and more than 15 reviewed publications. His research fields include synthetic aperture radar (SAR) systems, reflector-based SAR, digital beamforming for radar, synchronization of bistatic SAR, forward looking radar, and antennas. $\mathrm{He}$ is a Lecturer with the Universität Karlsruhe and gives courses for Carl-Cranz Geselchaft.

Dr. Younis is a member of the German Association for Location and Navigation. He is a Working Group Leader within the IEEE Instruments and Future Technologies Technical Committee. He received the Hermann-Billing award for his Ph.D. dissertation in 2005.

Alberto Moreira (Fellow, IEEE) was born in São José dos Campos, Brazil, in 1962. He received the B.S.E.E. and M.S.E.E. degrees from the Aeronautical Technological Institute ITA, Brazil, in 1984 and 1986, respectively, and the Dr.Eng. degree (honors) from the Technical University of Munich, Germany, 1993.

In 2003, he became a Professor from the University of Karlsruhe, Germany, in the field of microwave remote sensing. As its Chief Scientist

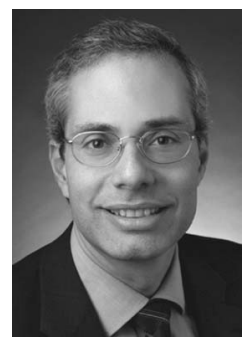
and Engineer, he managed from 1996 to 2001 the SAR Technology Department of the Microwaves and Radar Institute, German Aerospace Center (DLR). Under his leadership, the DLR airborne SAR system, E-SAR, has been upgraded to operate in innovative imaging modes like polarimetric SAR interferometry and SAR tomography. Since 2001, he has been Director of the Microwaves and Radar Institute, DLR. The institute contributes to several scientific programs and space projects for actual and future air- and space-borne SAR missions like TerraSAR-X, TanDEM-X, and Sentinel-1. He is the Initiator and Principal Investigator for the TanDEM-X mission. He has contributed to the successful series of European SAR conferences (EUSAR) since 1996 as a member of the Technical Program Committee, Technical Chairman (2000), Awards Chairman (2002-2004), General Chairman (2006), and Co-Chairman (2008). He has participated in 19 IGARSS conferences, has more than 250 publications in international conferences and journals, and has received 15 patents in the radar and antenna field. His professional interests and research areas encompass radar end-to-end system design and analysis, innovative microwave techniques and system concepts, signal processing, and remote sensing applications.

Prof. Moreira is a member of the IEEE GRS-S Administrative Committee (1999-2001, 2004-2007, 2008-2009 as Executive VicePresident, 2010 as President). He was the Founder and Chair of the German Chapter of GRS-S (2003-2008), was an Associate Editor for IEEE Geoscience And Remote Sensing Letters (2003-2007), and since 2005 has been an Associate and Guest Editor for the IEEE TRANSACTIONS ON Geoscience And Remote Sensing (TGRS). From 2003 to 2008, he was a member of the Board of Directors of the Information Technology Society, German Association for Electrical, Electronic and Information Technologies. In 1995, he received the DLR Science Award. He and his colleagues received the GRS-S Transactions Prize Paper Awards in 1997, 2001 and 2007. He also received the IEEE Nathanson Award for Young Radar Engineer of the Year (1999) and the IEEE Kiyo Tomiyasu Field Award (2007). 